\title{
Significant Increases in Extreme Precipitation and the Associations with Global Warming over the Global Land Monsoon Regions
}

\author{
WENXIA ZHANG \\ State Key Laboratory of Numerical Modeling for Atmospheric Sciences and Geophysical Fluid Dynamics, Institute of \\ Atmospheric Physics, Chinese Academy of Sciences, Beijing, China \\ TIANJUN ZHOU \\ State Key Laboratory of Numerical Modeling for Atmospheric Sciences and Geophysical Fluid Dynamics, Institute of \\ Atmospheric Physics, Chinese Academy of Sciences, and CAS Center for Excellence in Tibetan Plateau Earth Sciences, \\ Chinese Academy of Sciences, and University of Chinese Academy of Sciences, Beijing, China
}

(Manuscript received 2 October 2018, in final form 26 August 2019)

\begin{abstract}
The global land monsoon region, with substantial monsoon rainfall and hence freshwater resources, is home to nearly two-thirds of the world's population. However, it is overwhelmed by extreme precipitation, which is more intense than that on the rest of the land. Whether extreme precipitation has changed significantly, particularly in association with global warming, remains unclear for this region. This study investigates the presence of monotonic trends in extreme precipitation and its association with global warming over the past century over the global land monsoon regions, by employing the most comprehensive, long-running, and highquality observational extreme precipitation records currently available. Based on a total of 5066 stations with at least 50 years of records, we found significant increases in the annual maximum daily precipitation and associations with global warming in regional monsoon domains, including the southern part of the South African monsoon region, the South Asian monsoon region (dominated by India), the North American monsoon region, and the eastern part of the South American monsoon region during the period of 1901-2010, with responses to global warming of $\sim 10.4 \%-14.2 \% \mathrm{~K}^{-1}, 7.9 \%-8.3 \% \mathrm{~K}^{-1}, 6.4 \%-10.8 \% \mathrm{~K}^{-1}$, and $15.1 \%-$ $24.8 \% \mathrm{~K}^{-1}$, respectively. For the global monsoon region as a whole, significant increases in extreme precipitation and associations with global warming are also identified, but with limited spatial coverage. The qualitative results on the significance of the changes on the regional scale are generally robust against different time periods, record lengths of stations, and datasets used. The uncertainty in the quantitative results arising from limited spatial and temporal coverages and use of different datasets deserves attention.
\end{abstract}

\section{Introduction}

Changes in extreme precipitation, as the extreme sector of the hydrological cycle, under the ongoing anthropogenic warming have received enormous attention from both the climate research community and the public, due to the associated societal and economic losses. It has been consistently reported by the Fourth and Fifth Assessment Reports of the Intergovernmental Panel on Climate Change (IPCC) and the Special Report on Managing the Risks of Extreme Events and Disasters to Advance Climate Change Adaptation (SREX) that the number of heavy precipitation events over land has likely increased in more regions than it has

Corresponding author: T. Zhou, zhoutj@lasg.iap.ac.cn decreased since the 1950s (Trenberth et al. 2007; Seneviratne et al. 2012; Hartmann et al. 2013).

Within the global land region, the global land monsoon region is one of the most impacted by extreme precipitation, probably linked to its abundant moisture transport from the adjacent oceans and favorable monsoonal circulation (black lines in Fig. 1; Zhang et al. 2018). As a planetary-scale circulation system driven by the annual variation in solar radiation, the global monsoon system exhibits coherent variations on the interannual, decadal, and multidecadal time scales, although accompanied by regional characteristics modulated by regional air-sea interactions and topography (Trenberth et al. 2000; Wang and Ding 2006, 2008; Zhou et al. 2008; Wu et al. 2009; Wang et al. 2012, 2013; Song and Zhou 2014; Wang et al. 2017; Yao et al. 2017). In 
(a)

HadEX2-CMA

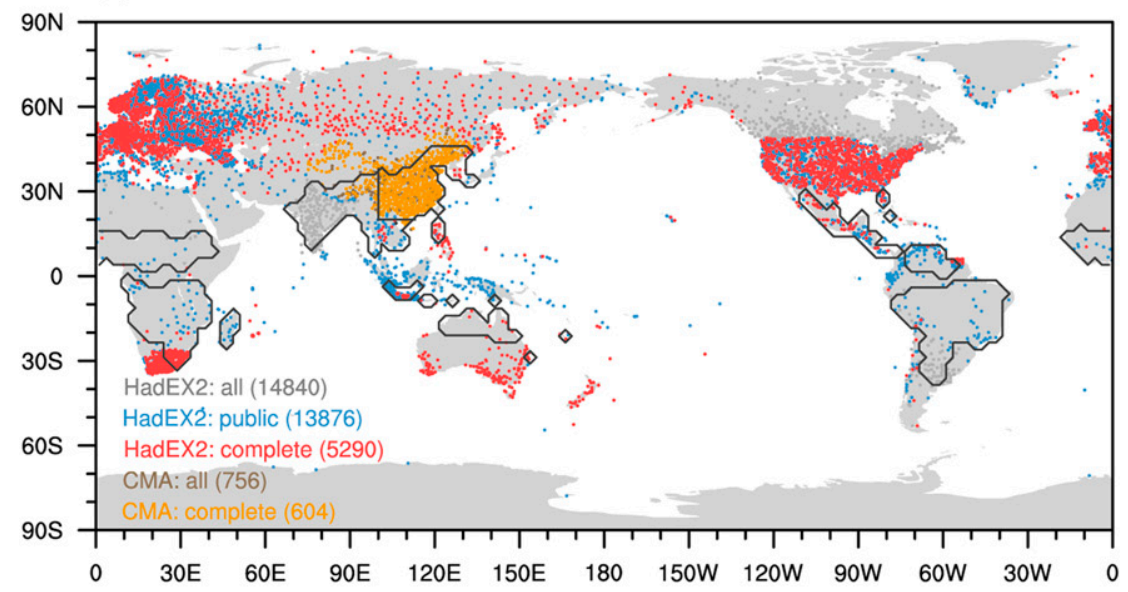

(b) GHCNDEX

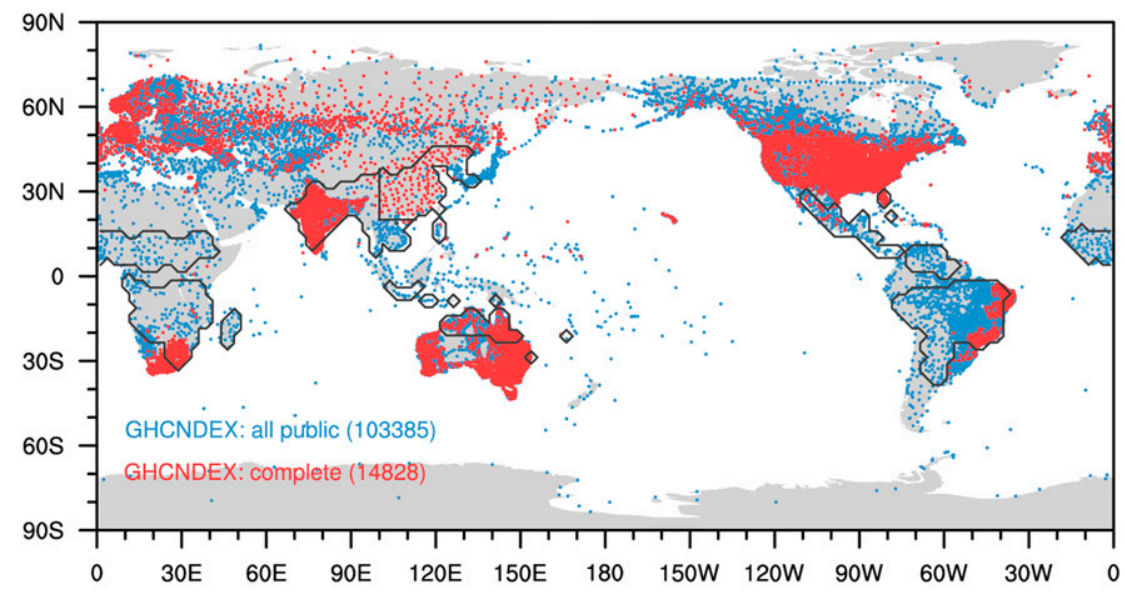

(c) HadEX2-GHCNDEX-CMA merged

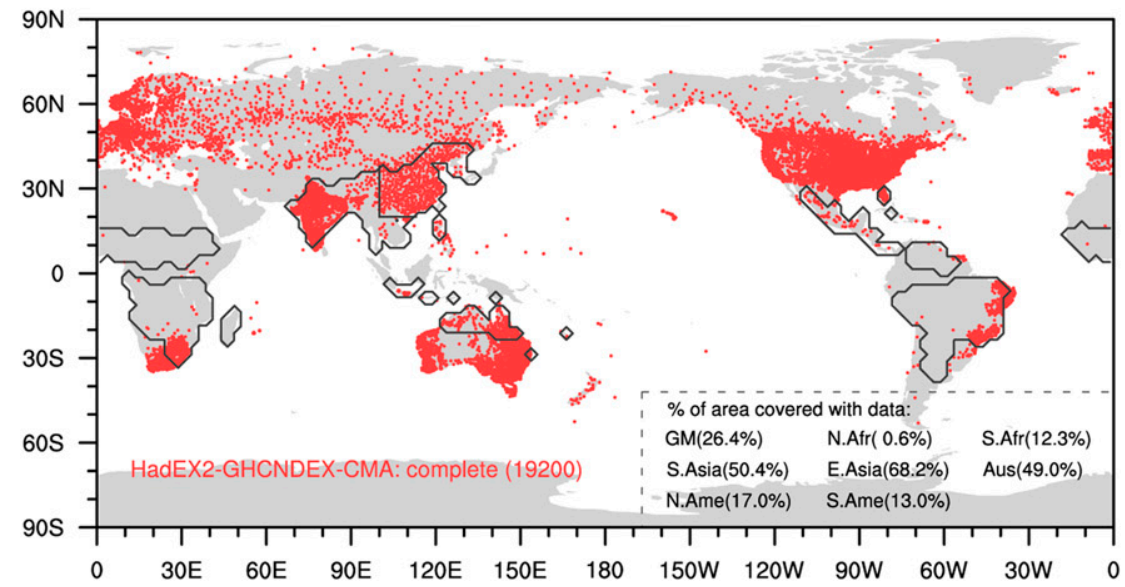

FIG. 1. Station distributions for Rx1day provided by HadEX2-CMA, GHCNDEX, and HadEX2-GHCNDEX-CMA merged datasets. (a) Stations for Rx1day indices provided by HadEX2 (gray), in which those that are publicly available are shown in blue and with complete records during 1901-2010 (with at least 50 years of records) are shown in red. Stations from the China Meteorological Administration (CMA) are used additionally with those with 
addition, the abundant monsoon rainfall supports nearly two-thirds of the world's population inhabiting the global land monsoon region. Understanding the past changes in extreme precipitation, particularly its possible link with global warming, is fundamental for the interpretation of past climate change and understanding of future projections, which is especially critical for the densely populated monsoon regions.

By theoretical arguments, extreme precipitation, predominantly fueled by moisture convergence, is expected to intensify with atmospheric moisture content, which increases at a rate of $\sim 7 \%$ per degree of global warming following the Clausius-Clapeyron relation (Allen and Ingram 2002; Trenberth et al. 2003). Indeed, the available in situ observations over the globe show a significant scaling in the annual maximum daily precipitation with the global mean near-surface temperature of between $5.9 \%$ and $7.7 \% \mathrm{~K}^{-1}$ over the past century (Westra et al. 2013). However, different from the uniform increase in the extreme precipitation expected from the above thermodynamic arguments, there is a notably large spatial variability in the observations (Groisman et al. 2005; Trenberth et al. 2007; Seneviratne et al. 2012; Hartmann et al. 2013; Westra et al. 2013; Donat et al. 2013a; Fischer and Knutti 2014; O'Gorman 2015). The diversity of the regional changes can be related to the effects of changes in the circulation, the moist adiabatic lapse rate, and the temperature when the extreme events occur (O'Gorman and Schneider 2009).

Regarding extreme precipitation changes in the monsoon regions, the majority of previous studies have examined the changes in individual monsoon regions. For example, there have been reports of significant increases in the intensity of wet spells and frequency of dry spells but decreases in the intensity of dry spells in the South Asian monsoon region since the 1950s, supported by increases in the moisture convergence and convective available potential energy, as well as large-scale circulation changes (Singh et al. 2014). Anthropogenic aerosols have played an important role in driving seasonal as well as daily scale changes in precipitation over various regions, and Asia in particular (Bollasina et al. 2011; Turner and Annamalai 2012). During the late twentieth century, the extreme precipitation decreased in India and northern China, while it increased in southern China, with aerosols contributing to this pattern of change (Lin et al. 2018; Singh et al. 2018). In the East Asian monsoon region, a significant shift in the precipitation spectrum from light to heavy precipitation (i.e., increases in the numbers of dry and heavy rain days and a decrease in the number of light rain days) is detected in the latter half of the twentieth century. In addition, the most extreme rainfall events became shorter in duration and more intense, with significant intensification occurring mainly in the southern part (Ma et al. 2015; Ma and Zhou 2015). Anthropogenic forcings are reported to play a role (Ma et al. 2017; Burke and Stott 2017). For China as a whole, however, significant influences of global mean temperature increases on extreme precipitation are not detected for 1961-2012 (Li et al. 2018). Additionally, the extreme precipitation in the East Asian and North American monsoon regions is also affected by tropical cyclones (Cavazos et al. 2008; Lau et al. 2008; Chang et al. 2012). In the North American monsoon region, heavy precipitation derived from tropical cyclones contributed increasingly to total extreme rainfall during 1961-98 (Cavazos et al. 2008). South America exhibited a general increase in extreme precipitation (except for in southern Peru and southern Chile) over 1960-2000, affected by an ENSO-like pattern of trends in the sea surface temperature (Haylock et al. 2006; Skansi et al. 2013). Over the past century, the Australian monsoon region has experienced an increase in extreme rainfall frequency, but few locations have shown significant trends in extreme precipitation intensity (King et al. 2013a). In southern and western Africa, there were increasing trends in the regionally averaged annual maximum 5-day and 1-day precipitation over 1961-2000, but only the trends for the latter are statistically significant (New et al. 2006).

To conclude, observational evidence has shown a general increase in either the frequency or intensity, or both, of heavy precipitation since the middle of the

\footnotetext{
complete records shown in yellow. (b) As in (a), but for GHCNDEX, in which all the station data are publicly available. (c) Station distributions of the HadEX2-GHCNDEX-CMA merged dataset with complete records during 1901-2010. The black lines denote the global land monsoon region defined by GPCP. The percentages of area covered with data (calculated on $1^{\circ} \times 1^{\circ}$ grid boxes) in each monsoon domain are shown in the bottom right. A grid box is considered covere if there is at least one station in it. GM: global land monsoon region; N.Afr: North African monsoon region; S. Afr: South African monsoon region; S.Asia: South Asian monsoon region; E.Asia: East Asian monsoon region; Aus: Australian monsoon region; N.Ame: North American monsoon region; S.Ame: South American monsoon region.
} 
twentieth century over the monsoon regions, although with strong spatial variations in the trends and significance levels. Nevertheless, there is no consensus yet on the underlying physics, particularly on the links with global warming in the observed changes in the global monsoon region. We do note that studies on the global scale have demonstrated a larger increase in the observed annual maximum daily rainfall than would be expected by chance and further an attributable influence from anthropogenic forcings (Min et al. 2011; Westra et al. 2013; Zhang et al. 2013). These studies, however, are mainly representative of the middle to high latitudes of the Northern Hemisphere, especially North America, Europe, and Asia, where dense observations are available. Specific attention on the global monsoon region that is mainly within the low latitudes is still lacking.

This study aims to reveal changes in the extreme precipitation over the global and regional land monsoon domains by employing the most comprehensive, longrunning, and high-quality observational records available at present. We aim to understand the association between the observed changes in the extreme precipitation and global warming. Specifically, the following scientific questions are addressed: 1) How did the extreme precipitation change over the past century over the global and regional land monsoon domains? 2) What is the relationship between the changes in extreme precipitation and global warming? 3) What are the robustness and uncertainty of the extreme precipitation changes?

The remainder of the paper is organized as follows. In section 2, we introduce the data and methods used in the paper. The results are presented in four subsections: section $3 \mathrm{a}$ examines the monotonic trends in extreme precipitation, section $3 \mathrm{~b}$ focuses on the association with global warming, and sections $3 \mathrm{c}$ and $3 \mathrm{~d}$ discuss the robustness and uncertainty of the results from different time periods and datasets, respectively. Finally, a summary of the results and concluding remarks are presented in section 4 .

\section{Data and methods}

\section{a. Observational data}

Two extreme precipitation indices, the annual maximum 1-day (Rx1day) and 5-day precipitation (Rx5day), are analyzed here, which are often referred to as proxies for flood risk (Zhang et al. 2011; Seneviratne et al. 2012). Three extreme precipitation datasets are used in this study to make the best use of the observations available at present.

1) Hadley Center Global Climate Extremes Index 2 (HadEX2), a quasi-global land-based dataset of climate extreme indices developed by the Expert Team on Climate Change Detection and Indices (ETCCDI; Zhang et al. 2011; Donat et al. 2013a). It is an update of HadEX, covering a longer period of 1901-2010 and containing more input station data from official rain gauge networks as well as regional collaborations (Alexander et al. 2006; Donat et al. 2013a). Most of the station data in HadEX2 have been carefully assessed for quality and adjusted for inhomogeneities. Thus, it represents the latest acquisition of high-quality station data around the globe. However, the station data in some regions, such as China and India, are not publicly available for HadEX2.

2) GHCNDEX extreme indices produced from the Global Historical Climatology Network's daily (GHCN-daily) precipitation (Donat et al. 2013b). This dataset utilizes only publicly available data and covers the period from as early as the 1860s (depending on the station) to the present. Although subjected to a comprehensive set of quality assurance procedures, the GHCN-daily data are not adjusted for artificial discontinuities resulting from changes in instrumentation, station location, etc. (Durre et al. 2010; Donat et al. 2013b). Both HadEX2 and GHCNDEX provide Rx1day and Rx5day indices defined by ETCCDI.

3) Daily precipitation observations from 756 stations in China from 1951 to the present from the China Meteorology Administration (CMA) are used to complement the above two datasets, as the station data over China are not publicly available from HadEX2 and those from GHCNDEX are sparse. This dataset has been subjected to quality controls and is recognized as an excellent one in the analyses of the long-term changes in extreme precipitation over China (Zhai et al. 2005; Li et al. 2018). To facilitate comparison, we calculate the extreme precipitation indices from daily observations strictly following the ETCCDI standard. The monthly (annual) index value is calculated only if fewer than 3 (15) days are missing in a month (year); otherwise it is set to a missing value. The annual index value is also set to missing if one of the monthly values is missing (Zhang et al. 2011).

As we focus on the long-term extreme precipitation changes, we study the period of 1901-2010 and select stations with at least 50 years of records during this period. This helps to reduce the effect of the decadal to multidecadal internal variability in the long-term changes. In addition, to investigate the robustness and uncertainty of the results, we also conduct sensitivity 
analyses using alternative time periods and record lengths, which qualitatively support our conclusions (see discussion in section 3c).

The station distributions are shown in Fig. 1. Taking Rx1day as an example, HadEX2 collects a total of 14840 stations across the globe, 13876 of which are publicly available (gray and blue dots in Fig. 1a, respectively). Our additional selection requiring at least 50 years of records during 1901-2010 produced 5290 stations over the globe (red dots in Fig. 1a). As stations in China are not publicly freely available from HadEX2, a set of 604 stations with at least 50 years of records over the study period from the CMA is selected to complement this dataset (hereafter, HadEX2-CMA; yellow dots in Fig. 1a). For GHCNDEX, although all the station records (103385) are publicly available, only 14828 of them are complete for analysis (blue and red dots in Fig. 1b).

Since the rain gauge networks of HadEX2 and GHCNDEX are largely independent (Herold et al. 2016), we thus produced a merged dataset (HadEX2GHCNDEX-CMA) from the three datasets to maximize the spatial coverage in the analysis, which provides a total of 19200 stations with complete records around the globe (Fig. 1c). Focusing on the global monsoon region, the three datasets provide 1369, 3866, and 5066 stations of extreme precipitation indices, respectively. The following analyses are thus based on the three quasi-global datasets, HadEX2-CMA, GHCNDEX, and the HadEX2-GHCNDEX-CMA merged dataset, which can be viewed as the most comprehensive, longrunning and high-quality observational datasets publicly available at present. We also note that the use of different datasets may introduce an important source of uncertainty to the results. A discussion of the uncertainty introduced by the different datasets is presented in section $3 \mathrm{~d}$.

Extreme precipitation observations are limited in the low latitudes, leading to a lack of spatial coverage in the global monsoon regions (Fig. 1c). We quantify the percentages of area covered with data for the monsoon domains on $1^{\circ} \times 1^{\circ}$ grid basis. A grid box is considered covered if there is at least one station in it. Stations are rare in the North African monsoon region, which prevents the analysis of this region. The stations in the South African and South American monsoon regions are concentrated in the southern and eastern parts, which only cover $12.3 \%$ and $13.0 \%$ of the monsoon domains, respectively. The East Asian, South Asian, and Australian monsoon regions are better covered with observations, with $68.2 \%, 50.4 \%$, and $49.0 \%$ of the area covered, respectively (Fig. 1c). Thus, for regional monsoon domains, we should specify the exact spatial coverages that the analyses represent. The results for the entire global monsoon region should thus be interpreted with caution, with $26.4 \%$ of the area covered with data, particularly due to the limited observations over the African and American monsoon regions.

In terms of the time span, the selected stations generally well cover the whole study period from 1901 to 2010 for the entire global monsoon region and for most of the subregions (Fig. 2). However, the limited time span should be noted for the South and East Asian monsoon regions. For the East Asian monsoon region, observations in China do not extend before the 1950s (Fig. 2e). For the South Asian monsoon region, the observations in India that are publicly available largely decline after the 1970s (Fig. 2d).

To investigate the association of extreme precipitation changes with global warming, surface temperature data from the National Aeronautics and Space Administration (NASA) Goddard Institute for Space Studies (GISS) is employed (Hansen et al. 2010). Note that the global mean surface temperature anomalies from different temperature datasets show good consistency, with much smaller differences between datasets than the interannual variability and long-term trend (Kennedy et al. 2010; Hartmann et al. 2013).

\section{b. Definition of global land monsoon region}

The global land monsoon region is identified as the area where the difference between the local summer and winter precipitation rate exceeds $2.0 \mathrm{~mm} \mathrm{day}^{-1}$ and the local summer precipitation exceeds $55 \%$ of the annual total (Wang et al. 2012). Here, local summer refers to May through September for the Northern Hemisphere and November through March for the Southern Hemisphere; and vice versa. In this study, we define the global land monsoon region based on the 1979-2010 climatological precipitation from the Global Precipitation Climatology Project (GPCP; Adler et al. 2003). For regional divisions, the equator separates the Northern Hemispheric from the Southern Hemispheric monsoon region, $60^{\circ} \mathrm{E}$ separates the North African from the South Asian monsoon region, and $20^{\circ} \mathrm{N}$ and $100^{\circ} \mathrm{E}$ separate the South Asian from the East Asian monsoon region [see the map in Fig. 8 for individual monsoon domains, following Kitoh et al. (2013)].

\section{c. Mann-Kendall test}

To evaluate the monotonic trends in the extreme precipitation, the Mann-Kendall test is employed, which does not make any assumptions on the distribution of the data (Kendall 1955). We use a 5\% two-sided significance level here. 
(a) Global monsoon

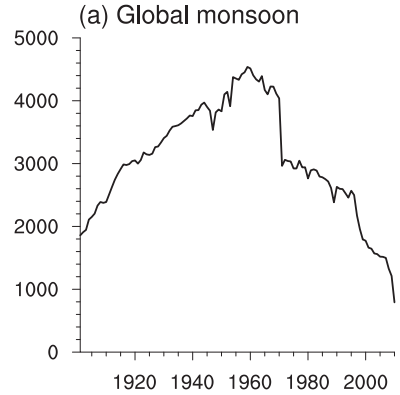

(e) East Asia

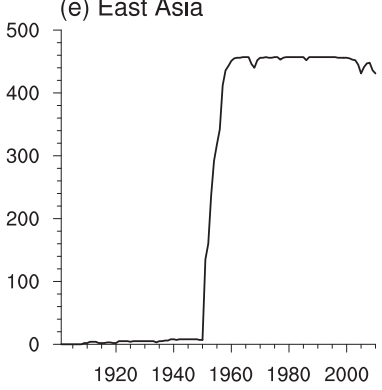

(b) North Africa

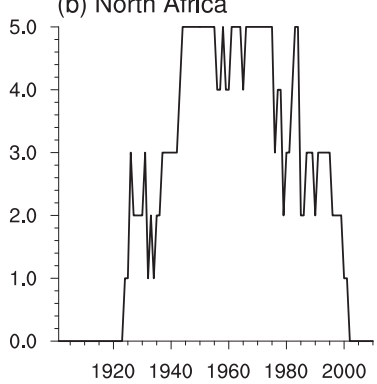

(f) Australia

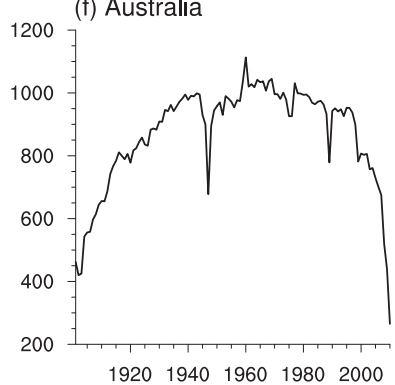

(c) South Africa

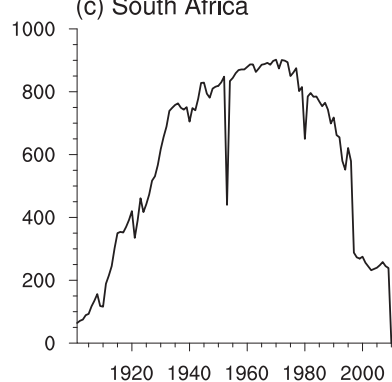

(g) North America

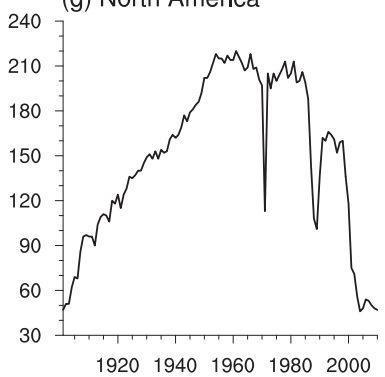

(d) South Asia

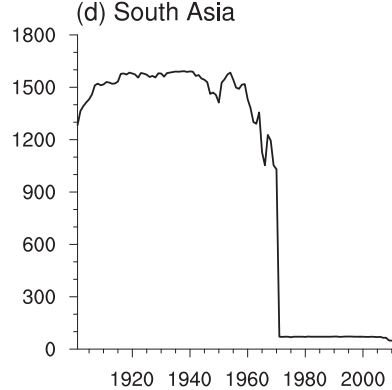

(h) South America

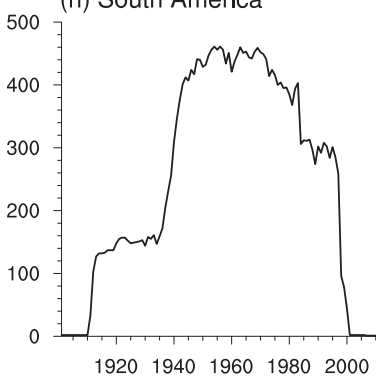

FIG. 2. The number of stations having records in each year from the HadEX2-GHCNDEX-CMA merged dataset during 1901-2010 for (a) the global monsoon region and (b)-(h) monsoon subregions. The stations are selected to have at least 50 years of records during 1901-2010.

\section{d. Field significance}

The Mann-Kendall test is performed for each station separately. To distinguish the large-scale climate change signals over a spatial domain, the field significance is assessed (von Storch and Zwiers 1999; Wilks 2006; Westra et al. 2013). This approach is especially useful for data with spatial dependence such as precipitation. The null hypothesis is that the observed pattern of change is due to random year-to-year fluctuations. The test statistic is the percentage of stations showing statistically significant trends from the Mann-Kendall test. This resampling-based procedure involves three steps. 1) Create 1000 bootstrapped fields by randomly drawing (with replacement) the time steps of the observational field but maintaining the spatial sequence across stations, thereby ensuring a realistic spatial structure of precipitation variability. The 1000 bootstrapped samples can be viewed as a set of plausible fields under random chance. 2) Calculate the test statistic (i.e., the percentage of stations showing statistically significant trends from the Mann-Kendall test in a region) on the 1000 resampled replicates, which form a null hypothesis distribution denoting the range of changes that could have occurred under random chance. 3) Compare the test statistic in the observation with the null hypothesis distribution. If the observed value is distinct from the null hypothesis distribution (falling outside the top $5 \%$ of the distribution), we then claim that the observed change is significant at the 5\% level. By comparing the observed change with that could have arisen from random chance, the field significance test assesses whether significant changes have emerged over a region in the observations (Alexander et al. 2006; Wilks 2006; Westra et al. 2013; Li et al. 2018).

We should note that a moving-block bootstrap is needed when there is significant autocorrelation in the time series (Wilks 2006). According to Westra et al. (2013), the autocorrelation of the extreme precipitation in the twentieth century is close to zero on average across all available stations globally and using a block size of larger than one does not affect the results; we therefore adopt the conventional spatial bootstrap procedure in this study.

\section{e. Scaling with GMST changes}

The relationship between the extreme precipitation and global mean surface temperature (GMST) changes is first examined on the stations. For each station individually, the GMST time series is first masked according to the extreme precipitation series (i.e., where the extreme precipitation record is missing, the temperature is also set to missing). This ensures a strict correspondence between the two variables. To eliminate the influence of interannual variability and focus on long-term climate change signals, both the precipitation and temperature time series are smoothed by averaging 
over 8-yr periods with a 4-yr overlapping (i.e., 1901-08, 1905-12, ..., 2001-08) (e.g., Collins et al. 2013). The regression coefficient between the smoothed extreme precipitation and GMST is referred to as the response rate. The response rate is normalized with the 1901-2010 climatology and expressed in units of percent per degree of warming $\left(\% \mathrm{~K}^{-1}\right)$.

To estimate the global or regional average of the responses, while accounting for the uneven geographic distribution of gauges, we also produce a gridded response rate based on the station estimates. The globe is first divided into $1^{\circ}$ latitude $\times 1^{\circ}$ longitude grid boxes. Each grid box value is calculated as the mean response rate across all of the stations within it (Westra et al. 2013). We also tested by using the median response rate across all the stations within each grid box, which yields similar results. The regional averages are then derived as the mean or median of the area-weighted responses from the available grids.

The statistical significance of the associations between the changes in the extreme precipitation and GMST on the station and regional scales is assessed by the bootstrap analysis. On the station scale, we calculate the response rates of extreme precipitation for the observation and the 1000 bootstrap samples generated in section $2 \mathrm{~d}$. A significant association on a station is identified if the observed response rate is outside the $95 \%$ range of the bootstrap samples. For a region, we also calculate the regional median response rates for the observational field and the 1000 resampled fields generated in section $2 \mathrm{~d}$, which take into account the spatial interdependence of precipitation. If the observed regional response rate is outside the $95 \%$ range of the bootstrap samples, we then claim that there is a significant association between the global warming and extreme precipitation changes for the region as a whole.

\section{Results}

\section{a. Trend in extreme precipitation over 1901-2010}

The climatology of extreme precipitation is first validated within the three datasets (Fig. 3). Both the spatial distributions and magnitudes of the extreme precipitation are comparable among these three datasets, which confirms the reliability of the data used. Thus, we mainly focus on the results based on the HadEX2GHCNDEX-CMA merged dataset for conciseness in the following analyses. The global land monsoon region is excessively affected by extreme precipitation, with a generally greater intensity than on the rest of the land. The rainfall amount on the wettest day annually can reach up to $\sim 100 \mathrm{~mm}$ in the monsoon regions where observations are available (Fig. 3).
The presence of monotonic trends in the extreme precipitation is examined by the Mann-Kendall test in Fig. 4. Over the global land monsoon region, the stations showing significant increasing trends predominantly outnumber those showing significant decreasing trends. Overall in the global monsoon region, among the stations available, $8.1 \%(8.4 \%)$ of the stations exhibit significant increasing trends in Rx1day (Rx5day), while $3.9 \%$ (3.7\%) show significant decreases over 1901-2010 from the merged dataset (Table 1).

In spite of the general increasing pattern in the extreme precipitation over the global land monsoon region, distinct regional characteristics are prominent (Fig. 4). In addition to the general thermodynamic influence from global warming, the internal climate variability and local effects such as aerosols also play a role on the local and regional scales. A dipolar trend is seen in the East Asian, Australian, and the eastern part of the South American monsoon regions. In the East Asian monsoon region, extreme precipitation has intensified in the southern part while weakened in the north. This dipolar trend resembles that in the summer mean precipitation in the latter half of the twentieth century, often referred to as the "south flood-north drought" pattern, and is partly related to the interdecadal internal variability of the East Asian summer monsoon (Yu et al. 2004; Yu and Zhou 2007; Zhou et al. 2009; Li et al. 2010; Nigam et al. 2015). The west-east contrast of the extreme precipitation changes in the Australian monsoon region is possibly related to the Pacific sea surface temperature (SST) variabilities, as the mean and extreme precipitations in Australia are strongly modulated by the Pacific SST variabilities on the interdecadal to long-term scales (King et al. 2013b; Brown et al. 2016). For the eastern part of the South American monsoon region, wetter conditions are observed in the southern part, while some scattered drying trends are seen in the northeastern part. This is also partly contributed by variabilities in the Pacific SST (Haylock et al. 2006). In the South Asian monsoon region, while significant increases dominate the Indian subcontinent, significant decreases are seen in northern India. The observed decreases in extreme precipitation in northern India and the dipolar change pattern in eastern China, together, are also affected by anthropogenic aerosols, particularly via the aerosol-indirect effect (i.e., aerosol-cloud interactions), by reducing the surface solar radiation, cooling the adjacent ocean, and weakening moisture transport into these regions (Lin et al. 2018; Singh et al. 2018).

As discussed above, on the local or regional scale, the extreme precipitation is largely affected by internal variability or local effects such as aerosols. Thus, it is 


\section{Rx1day}

(a) HadEX2-CMA

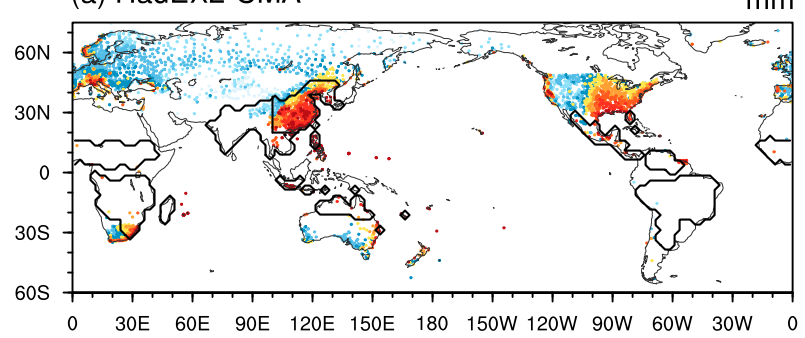

(c) GHCNDEX

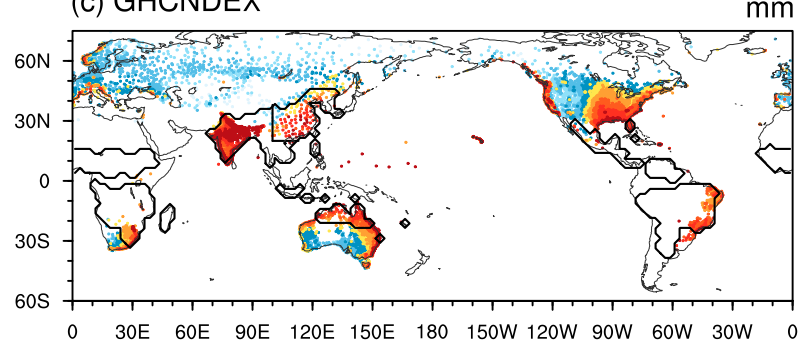

(e) HadEX2-GHCNDEX-CMA merged

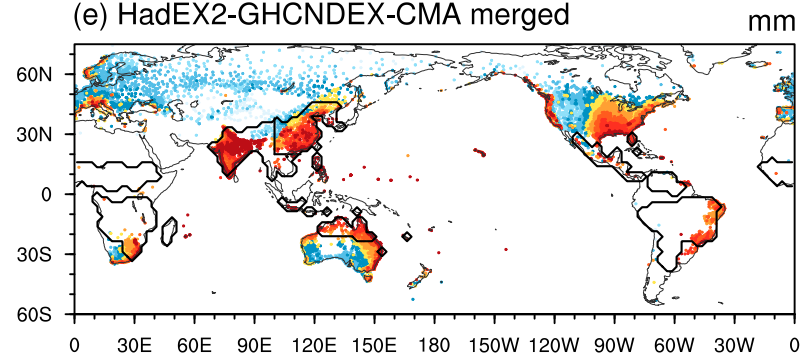

\section{Rx5day}

(b) HadEX2-CMA

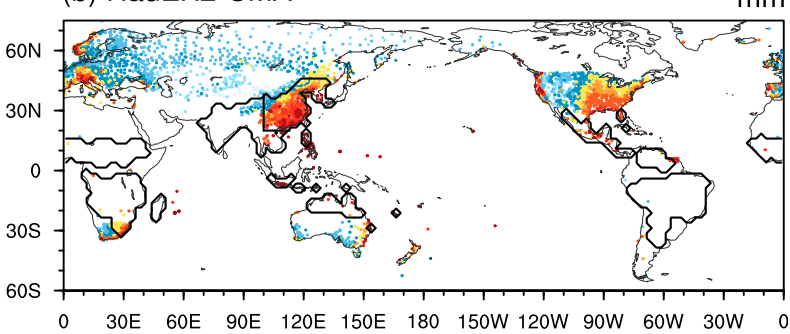

(d) GHCNDEX
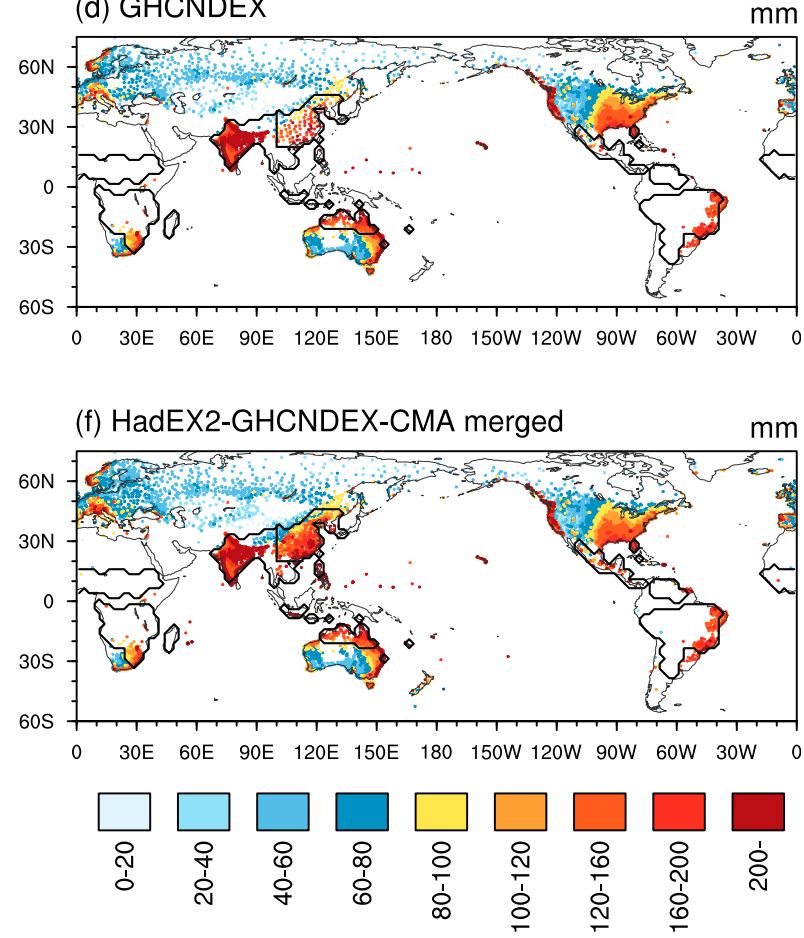

FIG. 3. Climatology of (left) Rx1day and (right) Rx5day in 1901-2010 from (a),(b) the HadEX2-CMA merged dataset, (c),(d) GHCNDEX, and (e),(f) the HadEX2-GHCNDEX-CMA merged dataset (mm).

difficult to separate the long-term climate change signals on these scales. One approach to reduce the effect of climate noise and better distinguish the climate change signals is spatial aggregation (e.g., Fischer et al. 2013; Fischer and Knutti 2014). Here, the field significance test from a spatial aggregation perspective is employed to examine whether there is a coherent and systematic change in the extreme precipitation in the monsoon regions, or whether the observed pattern of change can be represented as random fluctuations under climate noise (i.e., the null hypothesis).

We first examine the percentage of stations exhibiting significant increasing trends from the Mann-Kendall test (Fig. 5). The distributions from the 1000 bootstrap samples represent the plausible changes under the null hypothesis that there are no systematic trends in a region. For the global land monsoon region as a whole, the observed percentage of stations with significant increasing trends in extreme precipitation is well beyond the range of random chance at the $5 \%$ level (Fig. 5a). This indicates an overall pattern of increase in the extreme precipitation over the global land monsoon region. In contrast, the observed percentage of stations with significant decreasing trends is within the range of random chance (Fig. 6a).

Regionally, in the South African, South Asian, Australian, and North and South American monsoon regions, the observed percentages of stations showing significant increasing trends in extreme precipitation fall outside the null hypothesis distribution at the $5 \%$ level 
(a) Rx1day

HadEX2-GHCNDEX-CMA merged

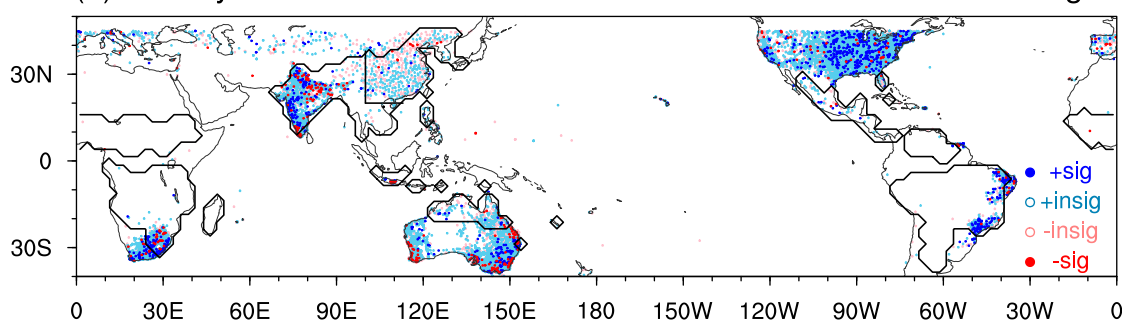

(b) Rx5day

HadEX2-GHCNDEX-CMA merged

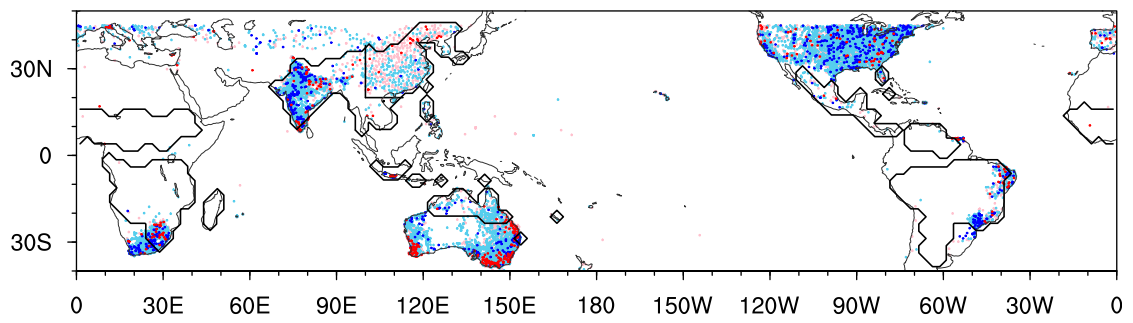

FIG. 4. The Mann-Kendall test for trends in (a) Rx1day and (b) Rx5day over 1901-2010 from the HadEX2-GHCNDEX-CMA merged dataset. The blue (red) dots indicate increasing (decreasing) trends in extreme precipitation, with filled dark blue (red) dots denoting statistically significant trends at the $5 \%$ level. For visualization purposes, the dark red dots overlay dark blue dots.

(Fig. 5). Nevertheless, the observed percentage of stations with significant increasing trends in the East Asian monsoon region falls within the null hypothesis distribution (Fig. 5e). On the other hand, the observed percentages of stations showing significant decreasing trends in extreme precipitation are not significantly different from the null hypothesis distributions in all the individual monsoon regions, except for Rx1day in the South Asian and Australian monsoon regions (Fig. 6). As discussed above, the systematic decreases in extreme precipitation in part of the South Asian and Australian monsoon regions may be related to aerosols and

TABLE 1. Number of observational stations available and median record length for Rx1day in monsoon regions, percentage of stations with increasing (decreasing) trends based on the Mann-Kendall test, positive (negative) associations with global mean temperature changes, and regional median scaling rates from the HadEX2-GHCNDEX-CMA merged dataset over 1901-2010 using stations with at least 50 years of records. Cases where fewer than 150 stations are available are indicated with a dash (-). An asterisk (*) indicates the $5 \%$ significance level for percentages of stations with significant increasing or decreasing trends based on the field significance test in column 5 and 5\% significance level for associations with global mean temperature changes based on bootstrap analyses in column 8 . See Fig. 1 for region abbreviation definitions.

\begin{tabular}{|c|c|c|c|c|c|c|c|}
\hline $\begin{array}{l}\text { Monsoon } \\
\text { region }\end{array}$ & $\begin{array}{c}\text { No. of } \\
\text { stations } \\
\text { included }\end{array}$ & $\begin{array}{l}\text { Median } \\
\text { record } \\
\text { length }(\mathrm{yr})\end{array}$ & $\begin{array}{c}\text { Stations } \\
\text { with }+(-) \\
\text { trends }(\%)\end{array}$ & $\begin{array}{l}\text { Stations with } \\
\text { significant }+(-) \\
\text { trends }(\% ; 5 \% \\
\text { significance level } \\
\text { from Mann- } \\
\text { Kendall test) }\end{array}$ & $\begin{array}{c}\text { Stations } \\
\text { with } \\
+(-) \\
\text { associations } \\
\text { with } \\
\text { GMST }(\%)\end{array}$ & $\begin{array}{c}\text { Stations with } \\
\text { significant }+(-) \\
\text { associations } \\
\text { with GMST } \\
(\% ; 5 \% \\
\text { significance level } \\
\text { from bootstrap } \\
\text { analysis) }\end{array}$ & $\begin{array}{c}\text { Regional } \\
\text { median } \\
\text { scaling } \\
\text { rate } \\
\left(\% \mathrm{~K}^{-1}\right)\end{array}$ \\
\hline GM & 5066 & 64 & $57.6(42.4)$ & $8.1 *(3.9)$ & $56.8(43.2)$ & $18.5(11.2)$ & $6.0^{*}$ \\
\hline N.Afr & 5 & 56 & - & - & - & - & - \\
\hline S.Afr & 964 & 65 & $60.6(39.4)$ & $9.0 *(2.1)$ & $65.5(34.5)$ & $19.9(7.5)$ & $10.4^{*}$ \\
\hline S.Asia & 1685 & 65 & $58.0(42.0)$ & $7.0^{*}\left(4.9^{*}\right)$ & $57.4(42.6)$ & $24.1(15.3)$ & $8.3^{*}$ \\
\hline E.Asia & 457 & 57 & $54.7(45.3)$ & $2.6(2.4)$ & $54.0(46.0)$ & $5.7(4.6)$ & 2.8 \\
\hline Aus & 1238 & 78 & $51.7(48.3)$ & $5.8\left(5.7^{*}\right)$ & $48.5(51.5)$ & $10.8(11.2)$ & -2.9 \\
\hline N.Ame & 229 & 70 & $53.7(46.3)$ & $8.3 *(2.6)$ & $54.1(45.9)$ & $12.7(11.4)$ & $10.8^{*}$ \\
\hline S.Ame & 488 & 55 & $70.1(29.9)$ & $21.3 *(1.6)$ & $63.5(36.5)$ & $30.3(10.5)$ & $15.1 *$ \\
\hline
\end{tabular}


(a) Global land monsoon

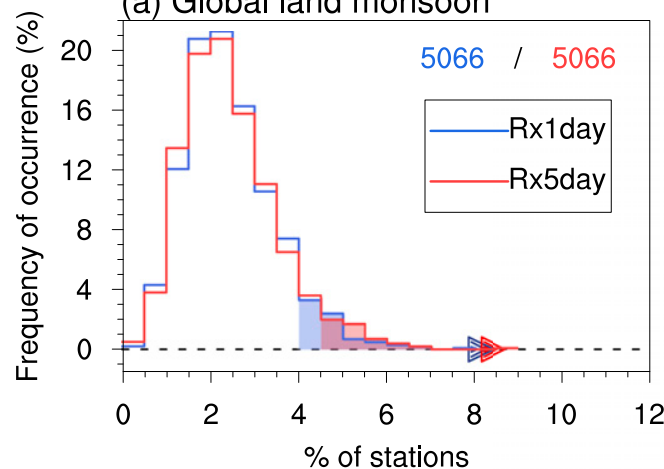

(c) South Africa

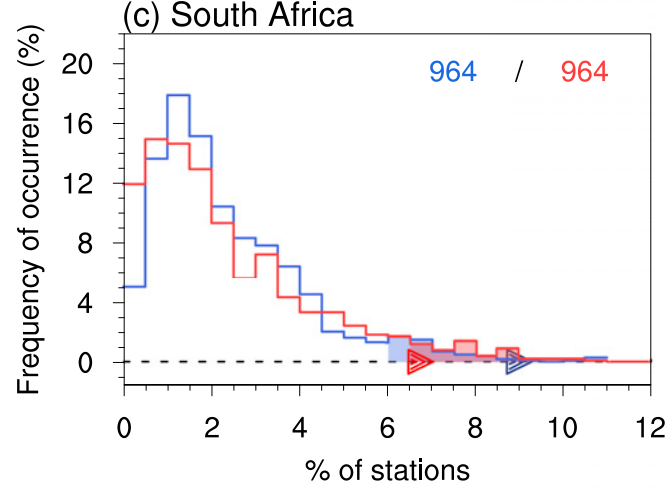

(e) East Asia

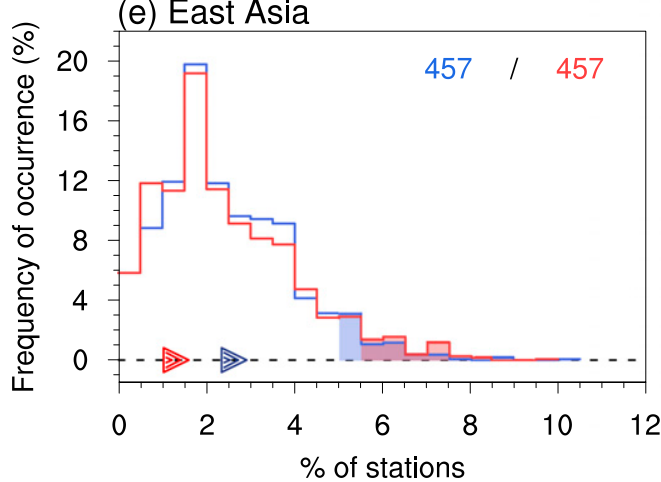

(g) North America

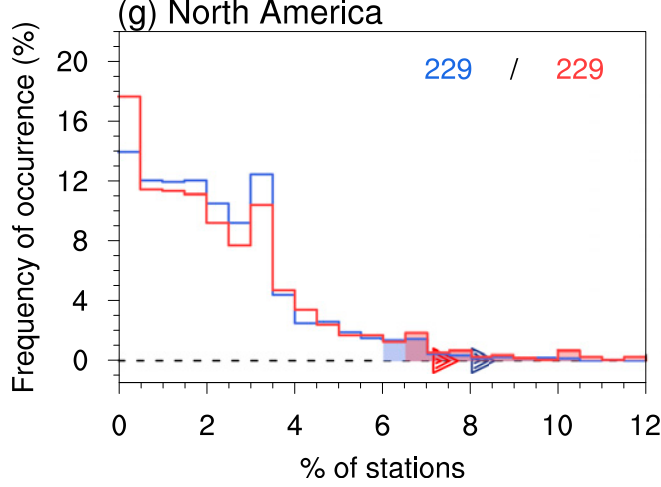

(b) North Africa

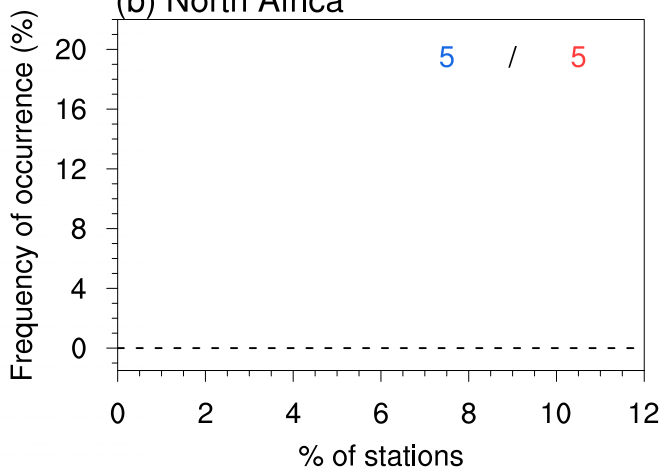

(d) South Asia
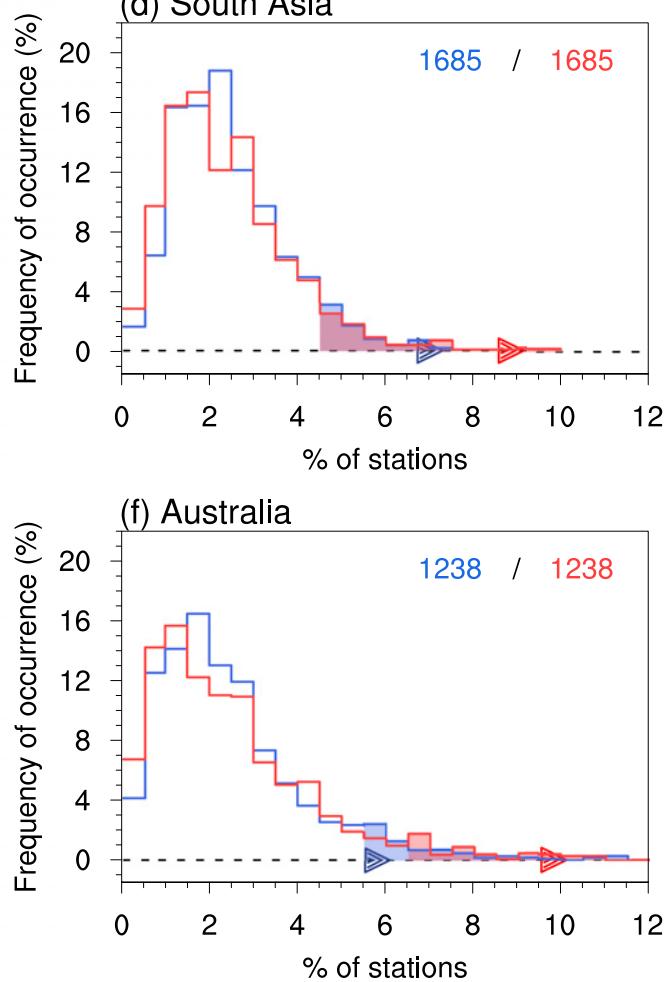

(h) South America

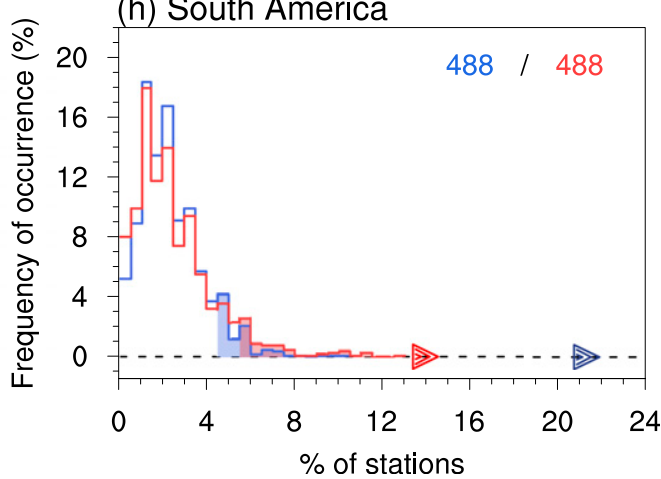

FIG. 5. Percentage of stations exhibiting statistically significant increasing trends in Rx1day (blue) and Rx5day (red) at the 5\% level based on the Mann-Kendall test during 1901-2010 from the HadEX2-GHCNDEX-CMA merged dataset, over the (a) global land monsoon region and (b)-(h) individual submonsoon regions. The histograms represent the distributions of results from 1000 bootstrap samples of the extreme precipitation data, with the upper 5\% shaded. The triangles indicate the observed values. Numbers of stations available within each region are shown at the top right. Results for cases where fewer than 150 stations are available are not shown. 
(a) Global land monsoon

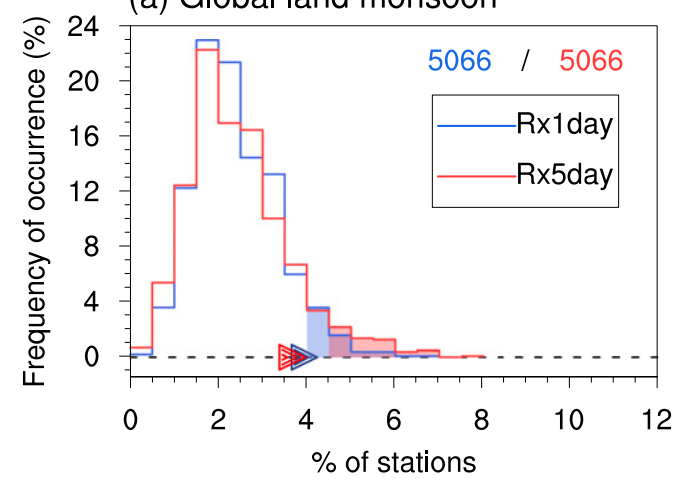

(c) South Africa

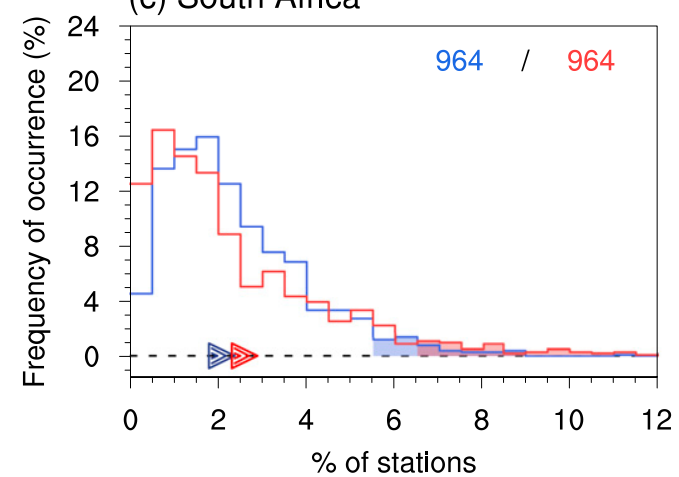

(e) East Asia

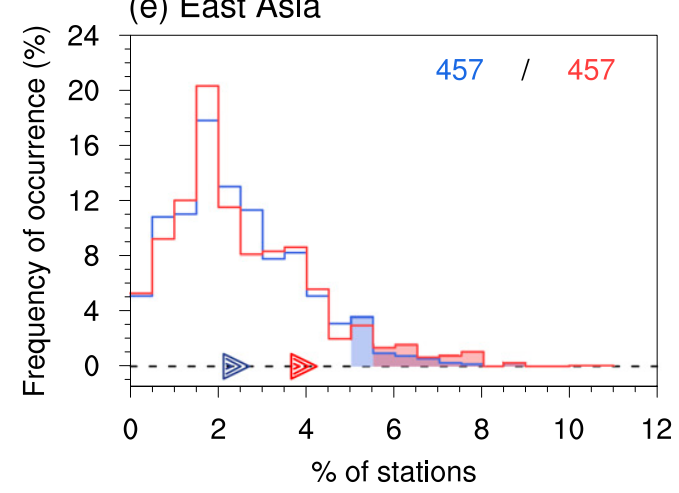

(g) North America

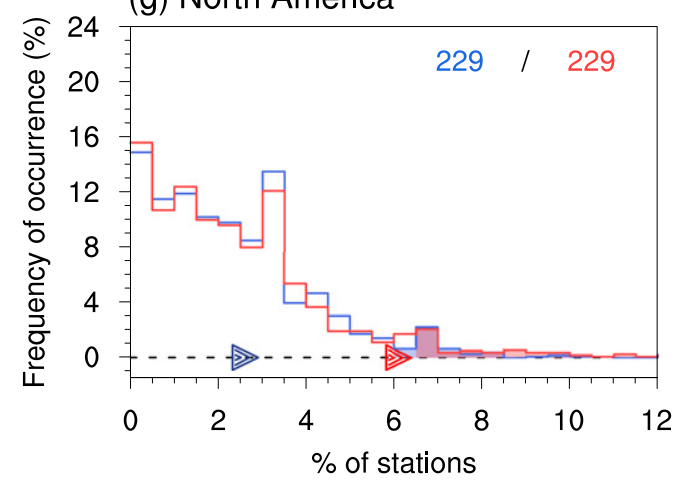

(b) North Africa

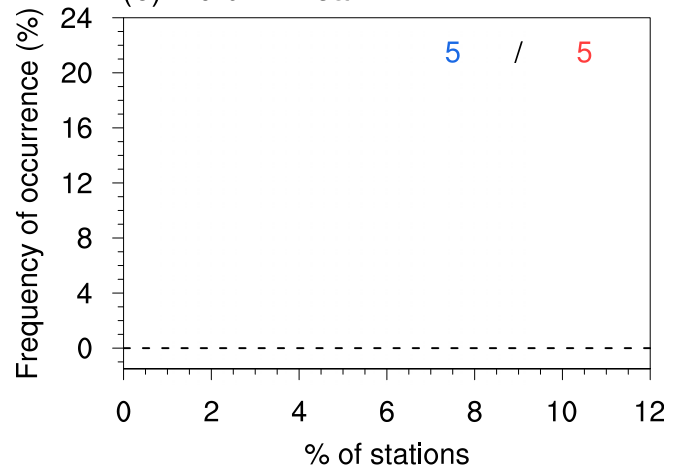

(d) South Asia
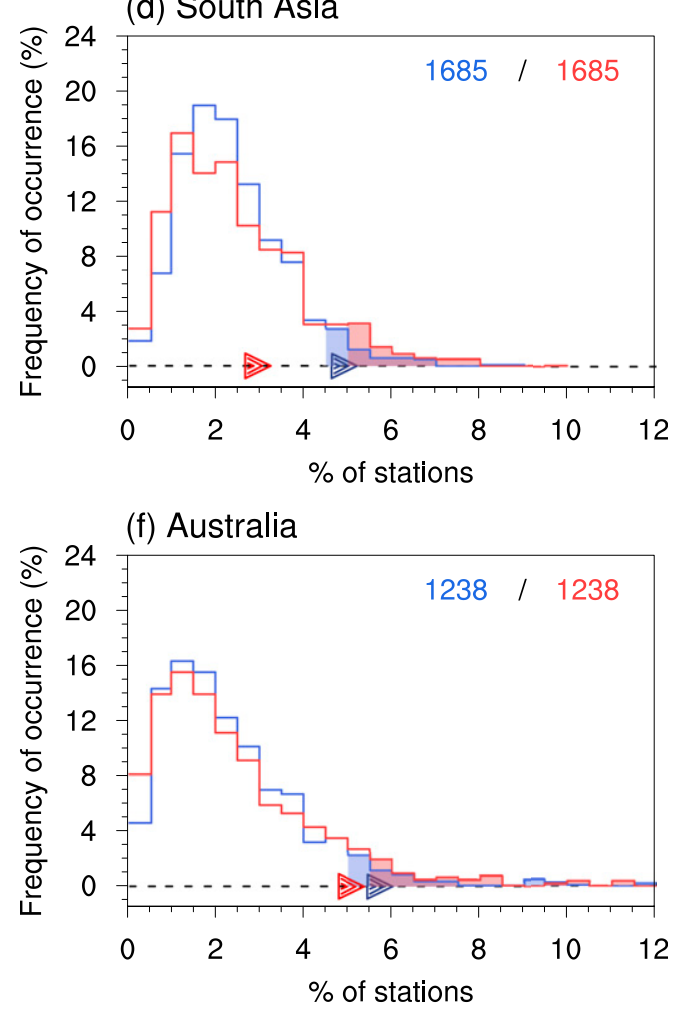

(h) South America

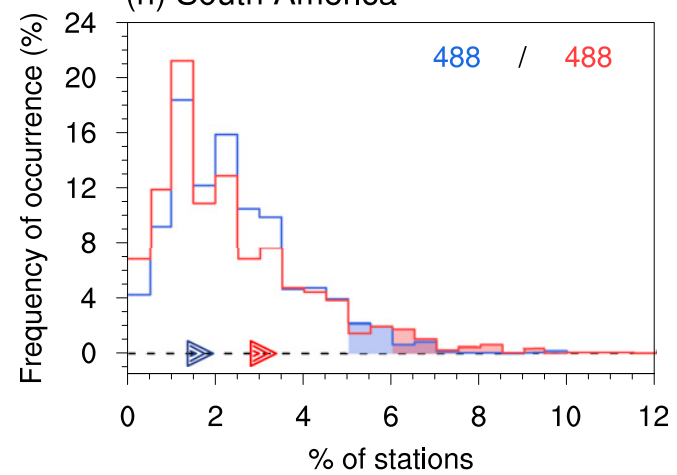

FIG. 6. As in Fig. 5, but for stations with statistically significant decreasing trends at the $5 \%$ level based on the Mann-Kendall test. 


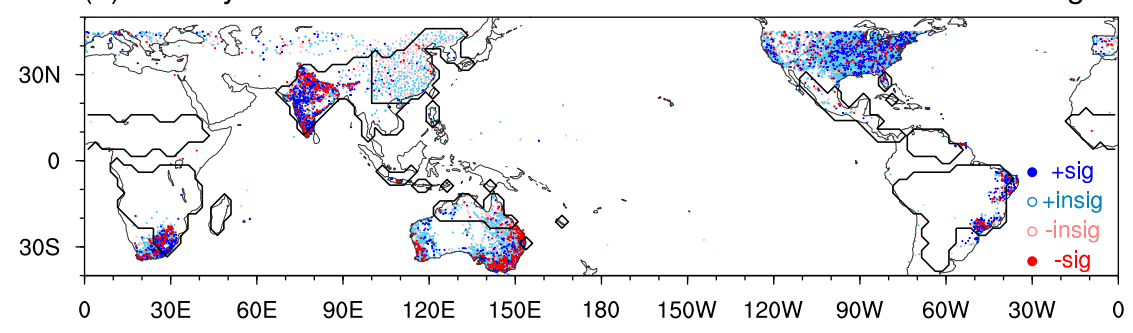

(b) Rx5day

HadEX2-GHCNDEX-CMA merged

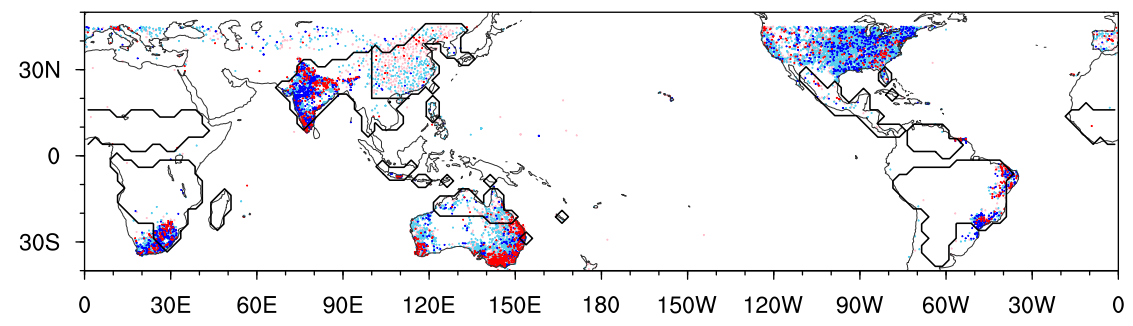

FIG. 7. Association of (a) Rx1day and (b) Rx5day to global mean near-surface air temperature (GMST) changes over 1901-2010 from the HadEX2-GHCNDEX-CMA merged dataset. The blue (red) dots indicate positive (negative) association with GMST, with filled dark blue (red) dots denoting statistically significant association at the $5 \%$ level indicated by the bootstrap analysis. For visualization purposes, the dark red dots overlay dark blue dots.

multidecadal SST variabilities in the Pacific, respectively (King et al. 2013b; Brown et al. 2016; Lin et al. 2018; Singh et al. 2018).

To conclude, by comparing the observations with the null hypothesis distribution, we identify an overall pattern of increase in the extreme precipitation for the global land monsoon region as a whole and for most of the monsoon subregions, which is significantly different from random chance.

\section{b. Relationship with GMST changes}

We now address this issue in more detail by examining the relationship between the extreme precipitation and GMST changes, referred to as the response rate here (section $2 \mathrm{e}$ ). To evaluate the significance of the response against the null hypothesis that there is no significant association, we adopt the bootstrap analysis. The test statistic (i.e., the response rate between the extreme precipitation and GMST) is calculated on both the observations and 1000 bootstrapped samples. If the observed response falls outside the $95 \%$ ranges of the bootstrap samples, a significant association between extreme precipitation and global warming is identified.

The response patterns of Rx1day and Rx5day resemble each other, which are also consistent with the monotonic trend patterns based on the Mann-Kendall test, confirming the robustness of the observed extreme precipitation changes (Figs. 7 and 4). On the station scale, $56.8 \%(43.2 \%)$ of the stations show positive (negative) scaling in Rx1day with GMST changes over the global land monsoon region derived from the HadEX2-GHCNDEX-CMA merged dataset, among which $18.5 \%$ (11.2\%) show significant responses, over 1901-2010 (Table 1). There are predominantly more stations responding positively in extreme precipitation to global warming than negatively.

We show the response rates of Rx1day zoomed in on each monsoon domain (Fig. 8). The extreme precipitation changes vary largely at the local scales. For the South Asian monsoon region, the largest responses are mainly seen along the Western Ghats and Himalayan foothills, implying the possible role of elevated topography in amplifying extreme precipitation. For the East Asian and Australian monsoon regions, the south-north and west-east contrast in extreme precipitation responses are seen. In other monsoon regions, the largest responses in extreme precipitation are generally randomly distributed. The scattered distributions partly result from internal variability, topography, and local processes, and meanwhile are related to the different record lengths from one station to the next. Although the response of Rx1day to global temperature changes can even exceed $50 \% \mathrm{~K}^{-1}$ on stations, we emphasize that the changes on station scales are largely affected by noise. More sophisticated statistical approaches are required to obtain the signals of local extreme precipitation changes (e.g., Risser et al. 2019). 

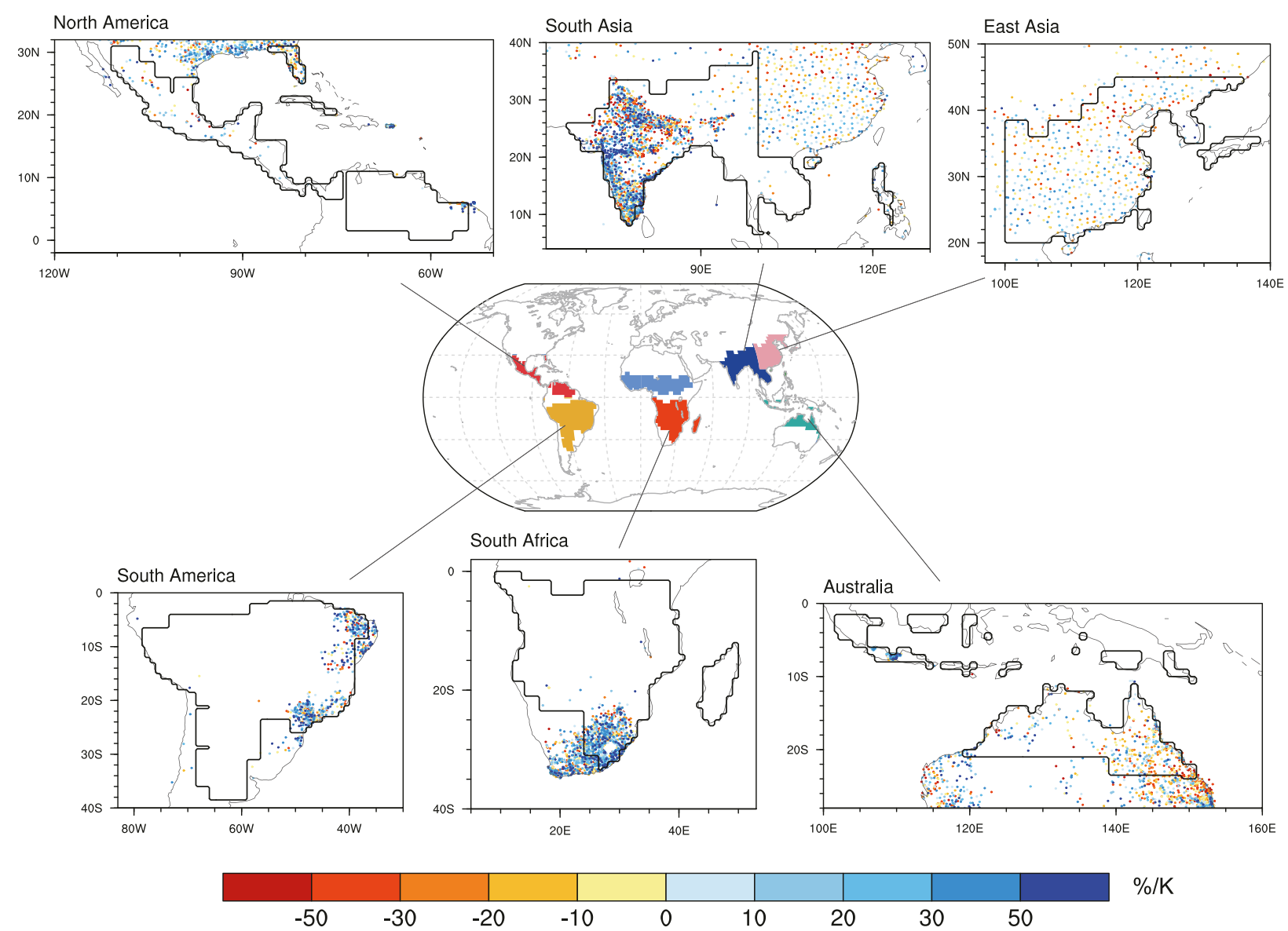

FIG. 8. Response of Rx1day to global mean near-surface air temperature changes over 1901-2010 from the HadEX2-GHCNDEX-CMA merged dataset over monsoon subregions $\left(\% \mathrm{~K}^{-1}\right)$. The map shows the division of monsoon subregions.

To account for the uneven distribution of the stations, the response rates calculated on each station are gridded onto $1^{\circ}$ latitude $\times 1^{\circ}$ longitude grid boxes. To reveal the overall changes within the monsoon regions, here we apply the spatially aggregated probability distribution. Figure 9 shows the distributions of the gridded response rate in the global land monsoon regions weighted by the area of each grid box. Thus, the histograms represent the percentages of areas experiencing certain responses. The $25 \%-75 \%$ range of the area (pink shadings in Fig. 9) have shown a sensitivity of between $-10.6 \%$ and $22.3 \% \mathrm{~K}^{-1}$ in $\mathrm{Rx} 1$ day for the global monsoon region as a whole. The regional median and mean response rates are estimated to be $6.0 \%$ and $7.5 \% \mathrm{~K}^{-1}$ for Rx1day, and $4.4 \%$ and $4.8 \% \mathrm{~K}^{-1}$ for $\mathrm{Rx} 5$ day, respectively, over 1901-2010 from the HadEX2-GHCNDEX-CMA merged dataset (Fig. 9a).

To address the issue of whether the observed extreme precipitation changes over the monsoon regions have significant associations with global warming or if they can be represented by random fluctuations of the climate system, the observed responses averaged in the monsoon regions are compared to the ranges of random chance generated from bootstrapping (Fig. 10). The area averages over the monsoon regions help to reduce the effects of internal climate variability and local effects. Therefore, the spread of the noise for the regional average responses is much smaller than that for the gridded responses (cf. Figs. 10 and 9), as the influence of climate noise such as internal variability is larger on smaller spatial scales. The results show that for the global land monsoon region as a whole (where observations are available), the change in Rx1day is significantly associated with global warming over the past century.

For the monsoon subregions, the distributions of the gridded response rate lie toward positive changes despite the large spread, indicating overall positive associations between extreme precipitation changes and the global temperature for the region as a whole, except for the Australian monsoon region (Figs. 9b-g). In agreement with the opposing changes within a region, the 
(a) Global monsoon

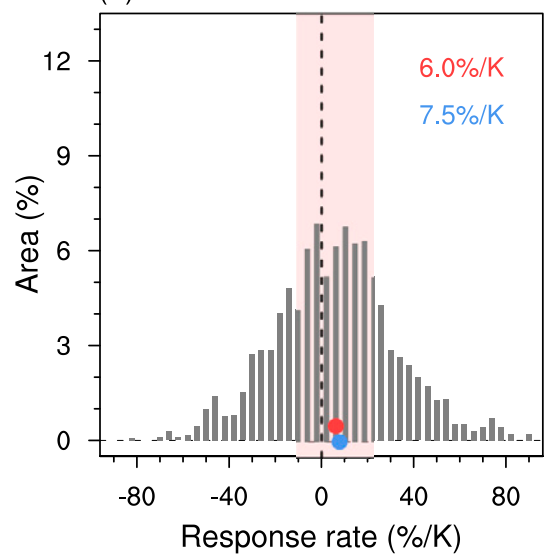

(c) South Asia

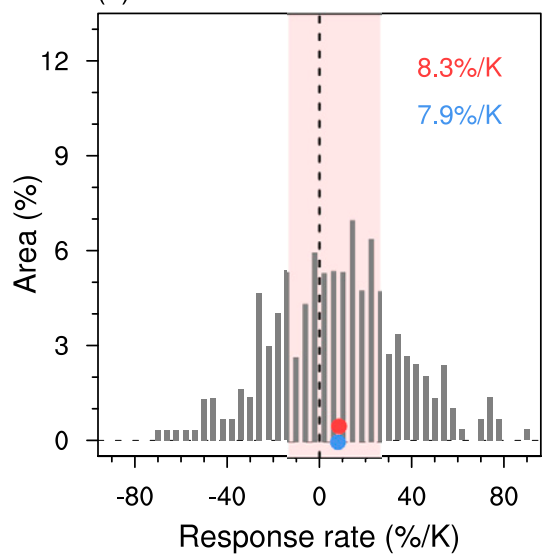

(b) South Africa

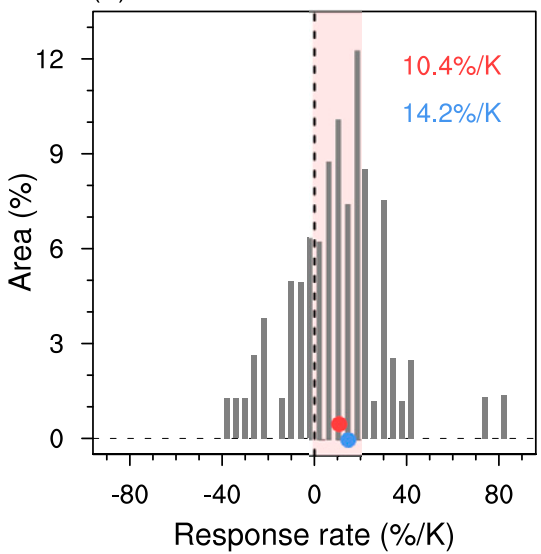

(d) East Asia

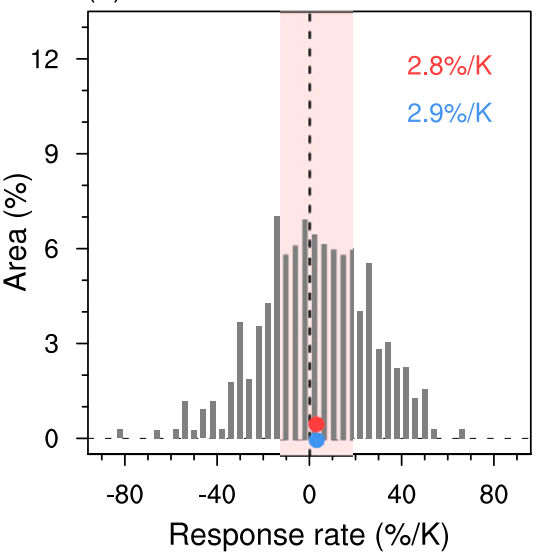

(e) Australia

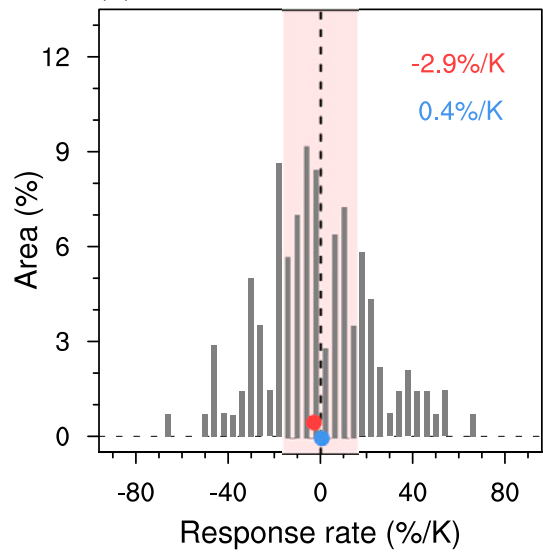

(f) North America

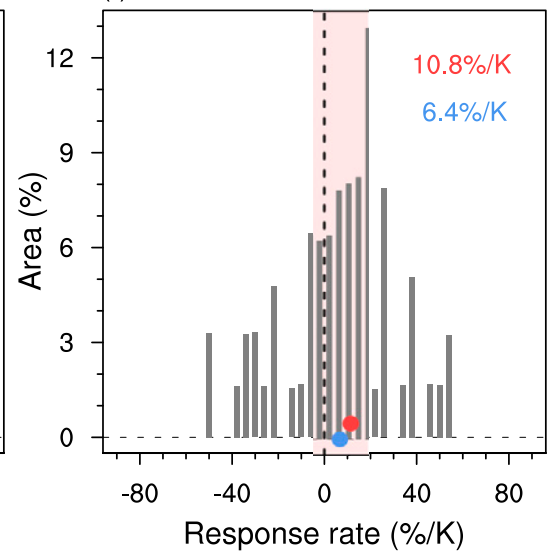

(g) South America

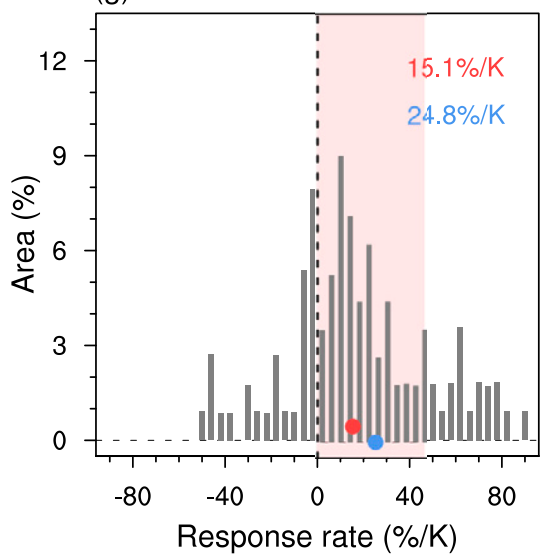

FIG. 9. Histograms of gridded scaling rates of Rx1day to global mean temperature changes over 1901-2010 for the global land monsoon regions from the HadEX2-GHCNDEX-CMA merged dataset. The abscissa represents the scaling rates $\left(\% \mathrm{~K}^{-1}\right)$, and the ordinate represents the fraction of area showing specific responses. The area-weighted median and mean scaling rates are indicated in red and blue, respectively. The pink shadings indicate the 25th-75th ranges of scaling rates with area-weighting. The results for the North African monsoon region are not shown as fewer than 150 stations are available. 

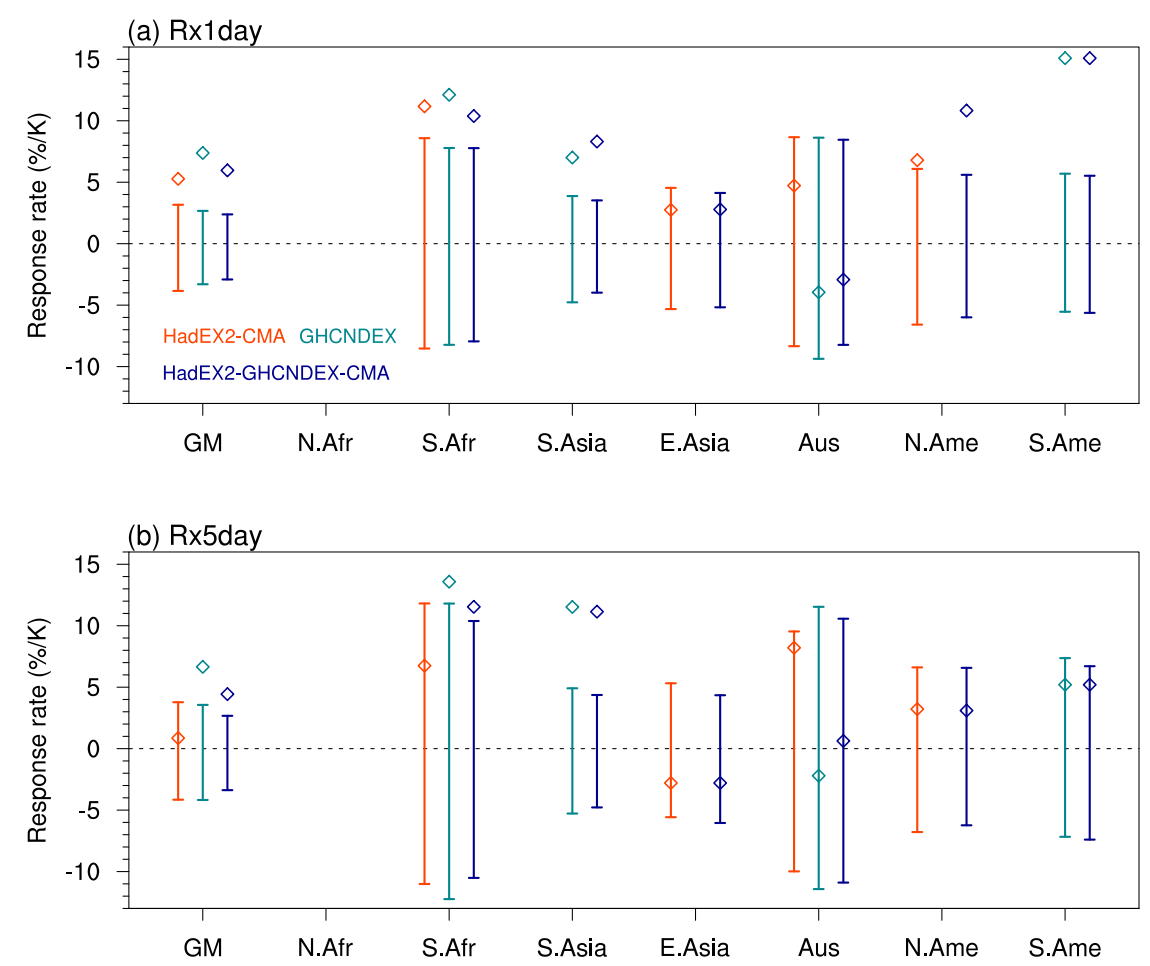

FIG. 10. Response of (a) Rx1day and (b) Rx5day to global mean temperature changes over 1901-2010 in the global land monsoon regions $\left(\% \mathrm{~K}^{-1}\right)$. The diamonds indicate observed regional values estimated from medians of all the grids available within a region. The error bars indicate the $95 \%$ ranges from 1000 bootstrap realizations. Cases where fewer than 150 stations are available are not shown.

histograms for the South Asian, Australian, and South American monsoon regions show bimodal distributions, which indicate increases in the regional contrast of the changes and reflect the possible influences from aerosols and multidecadal SST variabilities over the past century. In terms of the regional averages, the southern part of the South African monsoon region, the South Asian monsoon region (dominated by India), the North American monsoon region, and the eastern part of the South American monsoon region have exhibited significant associations between Rx1day changes and global warming, at rates of approximately $10.4 \%$ $14.2 \% \mathrm{~K}^{-1}, \quad 7.9 \%-8.3 \% \mathrm{~K}^{-1}, \quad 6.4 \%-10.8 \% \mathrm{~K}^{-1}$ and $15.1 \%-24.8 \% \mathrm{~K}^{-1}$, respectively, depending on the methods of estimation, as estimated from the merged dataset. Nevertheless, the regional average changes in the East Asian and Australian monsoon regions are small and do not exhibit significant associations with global warming, primarily related to the dipolar patterns of changes within these regions associated with the multidecadal internal variability (Fig. 10a). We also note that the spread of noise of the regional average responses is larger for the Australian and South African monsoon regions than for the other monsoon subregions
(Fig. 10). This may be partly related to the generally smaller spatial coverages for the Australian and South African (only the southern part is included in the analysis) monsoon regions, as the average across a larger spatial domain tends to reduce the effect of climate noise to a larger extent. In addition, there are regional mechanisms influencing the regional extreme precipitation other than global warming (e.g., SST variability, tropical cyclones, land use), which may also influence the range of noise among different regions.

Although the changes in Rx1day and Rx5day are qualitatively similar in terms of the spatial pattern (Figs. 4 and 7), the associations between Rx5day and the temperature changes are generally weaker than those between Rx1day and the temperature changes. For the North and South American monsoon regions, the associations between Rx1day and global warming are significant over the past century but insignificant for Rx5day (Fig. 10). According to the thermodynamic arguments, the more intense extremes such as Rx1day are largely controlled by the moisture availability, which is directly related to the thermal conditions of the atmosphere and hence the global mean temperature (Allen and Ingram 2002; Trenberth et al. 2003). In addition, 
they may be further amplified by the feedbacks of increased latent heat release (Lenderink and van Meijgaard 2008; Berg et al. 2013; Westra et al. 2014). Nevertheless, moderate extremes such as Rx5day with a larger temporal-spatial scale are to some extent regulated by the large-scale energy and circulation constraint, with an expected stabilization of the tropical atmosphere under global warming (Vecchi and Soden 2007; Pendergrass and Hartmann 2014; Pendergrass et al. 2015; Lin et al. 2016). This can be critical for the global monsoon region, which lies mainly in the tropics, and tends to weaken the association between these types of precipitation extremes and the background thermal conditions. As a result, the association of Rx5day with global warming is weaker than that of Rx1day.

To this end, we have examined the observed longterm changes in the extreme precipitation in the global monsoon regions and compared it with what would be expected from random chance. Particularly, the presence of a significant trend over a region is tested by the field significance of the percentage of stations within a region showing statistically significant increasing or decreasing trends from the Mann-Kendall test. Meanwhile, the significance of the association between extreme precipitation and global mean temperature changes is examined based on the bootstrap analysis. Since the global temperature has increased steadily over the past century, we may expect similar results from the two analyses.

Indeed, similar patterns of change are derived for the trend and association with GMST (Figs. 4 and 7). On the regional scale, the global land monsoon region as a whole, as well as the southern part of the South African monsoon region, the South Asian monsoon region (dominated by India), the North American monsoon region, and the eastern part of the South American monsoon region, has experienced significant increases in Rx1day and associations with global warming during 1901-2010. This consistency between the two analyses confirms the robustness of the results.

However, some differences are also seen from the two analyses. For example, for Rx1day in the Australian monsoon region and Rx5day in the Australian and North and South American monsoon regions, the observed percentages of stations showing significant monotonic increasing trends are outside the null hypothesis distributions (Fig. 5). However, the observed area average scaling relationships with the global mean temperature changes in these cases are insignificant (Fig. 10). Such differences may arise from several causes. First, the presence of monotonic trends does not necessarily correspond to a large sensitivity to global warming, and vice versa. Second, the test on the percentage of stations exhibiting significant trends is influenced by the uneven geographical distribution of the stations. Third, although the percentages of stations showing significant increasing or decreasing trends are statistically different from the null hypothesis distribution, the regional average responses can be small, as they are smoothed out by the opposing changes within a region, which may be related to the multidecadal climate internal variability, as in the case of the Australian monsoon region. Hence, in terms of the regional averages, significant associations between changes in the extreme precipitation and global warming have not emerged yet.

Thus, taking the potential differences in the two analyses into account, there are significant increases in Rx1day and associations with global warming in the global land monsoon region as a whole (where observations are available), as well as in the southern part of the South African monsoon region, South Asian monsoon region (dominated by India), North American monsoon region, and the eastern part of the South American monsoon region over the past century. The associations between the moderate precipitation extremes (e.g., Rx5day) and temperature are weaker than that of Rx1day.

The above results are generally representative of the whole study period covering the past century for the entire global monsoon region and most of the subregions, except for the South and East Asian monsoon regions (Fig. 2). For the South Asian monsoon region, the current study focuses on changes before the 1970s (Fig. 2d). Then do the revealed changes continue into the latter half of the twentieth century? Over India, the most prominent changes continue into the recent decades on the regional scale, including the increases in extreme precipitation in the western and central India while decreases in the northeast and southwest (Bisht et al. 2018; Mukherjee et al. 2018; Singh et al. 2019). On the other hand, it is also reported that on some locations, extreme precipitation trends reverse sign in the latter half of the twentieth century, possibly related to the urbanization during this period in India (Vittal et al. 2013; Bisht et al. 2018). Given the increasing complexity of local extreme precipitation changes in the recent decades, the quantitative responses estimated here should not be extended to the recent decades.

\section{c. Uncertainty from different time periods}

The above analyses are based on 1901-2010 employing 5066 stations over the global land monsoon region with at least 50 years of records, with a median record length of 64 years (Table 1). To assess the robustness of the results and potential influences from decadal to multidecadal climate internal variability, we perform 
TABLE 2. As in Table 1, but for changes in Rx1day over 1901-2010 using stations with at least 30 years of records.

\begin{tabular}{|c|c|c|c|c|c|c|c|}
\hline $\begin{array}{l}\text { Monsoon } \\
\text { region }\end{array}$ & $\begin{array}{c}\text { No. of } \\
\text { stations } \\
\text { included }\end{array}$ & $\begin{array}{l}\text { Median } \\
\text { record } \\
\text { length }(\mathrm{yr})\end{array}$ & $\begin{array}{c}\text { Stations } \\
\text { with }+(-) \\
\text { trends }(\%)\end{array}$ & $\begin{array}{c}\text { Stations with } \\
\text { significant }+(-) \\
\text { trends }(\% ; 5 \% \\
\text { significance level } \\
\text { from the } \\
\text { Mann-Kendall test) }\end{array}$ & $\begin{array}{c}\text { Stations with } \\
+(-) \\
\text { associations } \\
\text { with GMST }(\%)\end{array}$ & $\begin{array}{c}\text { Stations with } \\
\text { significant }+(-) \\
\text { associations with } \\
\text { GMST }(\% ; 5 \% \\
\text { significance level from } \\
\text { bootstrap analysis) }\end{array}$ & $\begin{array}{l}\text { Regional } \\
\text { median } \\
\text { scaling rate } \\
\left(\% \mathrm{~K}^{-1}\right)\end{array}$ \\
\hline GM & 9344 & 52 & $57.2(42.8)$ & $8.3^{*}(4.0)$ & $57.0(43.0)$ & $19.8(12.3)$ & $4.7 *$ \\
\hline N.Afr & 55 & 34 & - & - & - & - & - \\
\hline S.Afr & 1138 & 62 & $59.8(40.2)$ & $8.7 *(2.0)$ & $64.0(36.0)$ & $19.6(7.6)$ & $8.8^{*}$ \\
\hline S.Asia & 2310 & 62 & $55.6(44.4)$ & $6.8 *(5.4 *)$ & $55.6(44.4)$ & $24.9(16.5)$ & $5.2 *$ \\
\hline E.Asia & 567 & 56 & $51.9(48.1)$ & $2.1(2.5)$ & $51.5(48.5)$ & $7.4(7.2)$ & 1.5 \\
\hline Aus & 3388 & 40 & $54.7(45.3)$ & $7.7 *(4.5)$ & $55.7(44.3)$ & $16.0(11.2)$ & 0.2 \\
\hline N.Ame & 435 & 50 & $60.0(40.0)$ & $8.0 *(3.2)$ & $56.3(43.7)$ & $14.9(12.6)$ & $6.0^{*}$ \\
\hline S.Ame & 1451 & 44 & $65.3(34.7)$ & $14.1 *(2.6)$ & $59.3(40.7)$ & $27.1(13.0)$ & $15.7 *$ \\
\hline
\end{tabular}

the analyses using different time periods and record lengths as thresholds to select stations. Specifically, we compare the results for 1901-2010 using stations with at least 30 and 50 years of records, and for 1951-2010 using stations with at least 30 and 40 years of records (Tables 1-4). We do not compare the results for the first half of the twentieth century, as this largely reduces the spatial coverage for the global monsoon region (figure not shown). We mainly illustrate the results of Rx1day for conciseness.

For the use of different record lengths as thresholds to select stations, although a reduced number of stations are available when longer record lengths are required, the spatial patterns of change are similar (cf. Fig. 7a vs Fig. 11a; Fig. 11b vs Fig. 11c). For the different time periods considered (i.e., 1901-2010 vs 1951-2010), the patterns of change are also similar, with a major difference in India where the observational records are too short to be included in the latter half of the twentieth century (Figs. 7a and 11a-c). The different spatial coverages directly affect the regional average changes. For example, a significant association between the changes in Rx1day and global warming is identified for 19012010 for the South Asian monsoon region (dominated by changes in India), whereas it is not for 1951-2010 (dominated by changes in the Indo-China Peninsula) (Fig. 11). This highlights the importance of specifying the spatial coverages that the analyses represent.

In spite of this difference in the spatial coverage of India, the significance of the regional changes in Rx1day are consistent across the time periods considered, in terms of both the field significance of the trend and the significance of the association with global warming for the monsoon subregions (Tables 1-4, Fig. 11d). Thus, there are significant increases in Rx1day and associations with global warming for the global land monsoon region as a whole (where observations are available), as well as in the southern part of the South African monsoon region, the South Asian monsoon region (dominated by India), the North American monsoon region, and the eastern part of the South American monsoon region over the past century. This qualitative conclusion

TABLE 3. As in Table 1, but for changes in Rx1day over 1951-2010 using stations with at least 30 years of records.

\begin{tabular}{|c|c|c|c|c|c|c|c|}
\hline $\begin{array}{l}\text { Monsoon } \\
\text { region }\end{array}$ & $\begin{array}{c}\text { No. of } \\
\text { stations } \\
\text { included }\end{array}$ & $\begin{array}{c}\text { Median } \\
\text { record } \\
\text { length } \\
(\mathrm{yr})\end{array}$ & $\begin{array}{c}\text { Stations } \\
\text { with }+(-) \\
\text { trends }(\%)\end{array}$ & $\begin{array}{c}\text { Stations with } \\
\text { significant }+(-) \\
\text { trends }(\% ; 5 \% \\
\text { significance level } \\
\text { from the } \\
\text { Mann-Kendall test) }\end{array}$ & $\begin{array}{c}\text { Stations } \\
\text { with }+(-) \\
\text { associations } \\
\text { with GMST } \\
(\%)\end{array}$ & $\begin{array}{c}\text { Stations with } \\
\text { significant }+(-) \\
\text { associations with } \\
\text { GMST }(\% ; 5 \% \\
\text { significance level from } \\
\text { bootstrap analysis) }\end{array}$ & $\begin{array}{c}\text { Regional } \\
\text { median } \\
\text { scaling rate } \\
\left(\% \mathrm{~K}^{-1}\right)\end{array}$ \\
\hline GM & 6231 & 40 & $56.0(44.0)$ & $7.1 *(3.4)$ & $56.3(43.7)$ & $14.3(8.4)$ & $5.0^{*}$ \\
\hline N.Afr & 30 & 36 & - & - & - & - & - \\
\hline S.Afr & 1012 & 42 & $63.5(36.5)$ & $5.7(1.6)$ & $59.5(40.5)$ & $17.7(6.8)$ & $9.3^{*}$ \\
\hline S.Asia & 168 & 48 & $55.4(44.6)$ & $6.0 *(1.8)$ & $57.7(42.3)$ & $9.5(3.0)$ & 4.2 \\
\hline E.Asia & 565 & 56 & $51.3(48.7)$ & $2.3(2.5)$ & $54.5(45.5)$ & $5.8(4.4)$ & 4.0 \\
\hline Aus & 3020 & 39 & $50.9(49.1)$ & $7.3 *(4.6)$ & $55.5(44.5)$ & $12.9(8.0)$ & -3.4 \\
\hline N.Ame & 397 & 42 & $62.2(37.8)$ & $7.3 *(2.8)$ & $55.4(44.6)$ & $14.6(11.6)$ & $11.3^{*}$ \\
\hline S.Ame & 1039 & 39 & $64.2(35.8)$ & $10.8 *(2.7)$ & $56.4(43.6)$ & $19.9(12.9)$ & $10.5^{*}$ \\
\hline
\end{tabular}


TABLE 4. As in Table 1, but for changes in Rx1day over 1951-2010 using stations with at least 40 years of records.

\begin{tabular}{|c|c|c|c|c|c|c|c|}
\hline $\begin{array}{l}\text { Monsoon } \\
\text { region }\end{array}$ & $\begin{array}{c}\text { No. of } \\
\text { stations } \\
\text { included }\end{array}$ & $\begin{array}{c}\text { Median } \\
\text { record } \\
\text { length } \\
(\mathrm{yr})\end{array}$ & $\begin{array}{c}\text { Stations } \\
\text { with }+(-) \\
\text { trends }(\%)\end{array}$ & $\begin{array}{c}\text { Stations with } \\
\text { significant }+(-) \\
\text { trends }(\% ; 5 \% \\
\text { significance } \\
\text { level from the } \\
\text { Mann-Kendall test) }\end{array}$ & $\begin{array}{c}\text { Stations } \\
\text { with }+(-) \\
\text { associations } \\
\text { with GMST } \\
\quad(\%)\end{array}$ & $\begin{array}{c}\text { Stations with } \\
\text { significant }+(-) \\
\text { associations } \\
\text { with GMST (\%; } 5 \% \\
\text { significance level from } \\
\text { bootstrap analysis) }\end{array}$ & $\begin{array}{c}\text { Regional } \\
\text { median } \\
\text { scaling } \\
\text { rate } \\
\left(\% \mathrm{~K}^{-1}\right)\end{array}$ \\
\hline GM & 3355 & 47 & $54.9(45.1)$ & $6.6 *(3.3)$ & $53.8(46.2)$ & $10.9(6.2)$ & $4.6^{*}$ \\
\hline N.Afr & 13 & 42 & - & - & - & - & - \\
\hline S.Afr & 649 & 45 & $64.3(35.7)$ & $6.6^{*}(1.5)$ & $59.8(40.2)$ & $14.3(4.3)$ & 9.6 \\
\hline S.Asia & 140 & 50 & - & - & - & - & - \\
\hline E.Asia & 534 & 57 & $51.7(48.3)$ & $2.2(2.4)$ & $54.9(45.1)$ & $5.8(3.7)$ & 4.3 \\
\hline Aus & 1281 & 48 & $45.7(54.3)$ & $5.6(5.2)$ & $46.5(53.5)$ & $6.5(6.9)$ & -3.9 \\
\hline N.Ame & 224 & 47 & $59.4(40.6)$ & $8.0 *(3.6)$ & $57.6(42.4)$ & $12.5(8.5)$ & $8.2^{*}$ \\
\hline S.Ame & 514 & 44 & $67.3(32.7)$ & $13.2 *(1.8)$ & $60.7(39.3)$ & $22.6(8.4)$ & $12.9^{*}$ \\
\hline
\end{tabular}

is robust against the time period studied and record length required, and not substantially affected by possible influences of the natural multidecadal variability.

On the other hand, quantitatively, there are slight differences in the response rates of extreme precipitation to global warming among the time periods and temporal coverages considered, which may be partly influenced by the natural multidecadal variability (Fig. 11d). For extreme precipitation in the East Asian and Australian monsoon regions, significant changes and associations with global warming have not emerged yet. This may also be related to influences of natural multidecadal variability, as seen from the dipolar patterns of change within these subregions.

\section{d. Uncertainty from different datasets}

To maximize the spatial coverage in the analysis, this work utilizes three datasets, HadEX2, GHCNDEX, and CMA. While HadEX2 is a high-quality station dataset with homogenization, it provides only limited stations in the low latitudes including the monsoon regions (Fig. 1a). Thus, GHCNDEX is used to fill part of the gaps, which has the limitation of not being corrected for discontinuities. The two datasets generally agree on the long-term changes in extreme precipitation, with a pattern correlation of 0.70 for the gridded scaling rates of Rx1day for 1901-2010 over the global monsoon region. The HadEX2-GHCNDEX-CMA merged dataset has a pattern correlation of 0.98 with both HadEX2-CMA and GHCNDEX. Nevertheless, the uncertainty from the different datasets, including their different spatial and temporal coverages and quality control procedures, requires particular attention in interpreting the results.

Figure 10 compares the association between the extreme precipitation and global warming for the monsoon regions among the three datasets. Qualitatively, the three datasets consistently reveal the significance of the association, except for Rx5day in the global and South African monsoon regions (Fig. 10b). Quantitatively, there are slight differences in the regional median response rates among the three datasets, which may arise from sampling variability (e.g., different spatial and temporal coverages of the records) and different quality control procedures.

We first examine the uncertainty that arises from the sampling variability of the datasets. Taking Rx1day as an example, for the global land monsoon region as a whole, the regional median response rates in HadEX2CMA and GHCNDEX are $5.3 \%$ and $7.4 \% \mathrm{~K}^{-1}$, respectively (Fig. 10a). To reduce the effect of the sampling variability, we compare the results by masking the gridded response rates in the two datasets into the same spatial coverage, retaining only the grids available in both of them (figure not shown). Consequently, the difference between HadEX2-CMA and GHCNDEX is reduced, with regional median response rates of $7.3 \%$ and $6.3 \% \mathrm{~K}^{-1}$, respectively, for the global monsoon region. Hence, the different spatial coverages they represent account for part of the uncertainty in the different observational datasets. To reduce this uncertainty, we only show the results for regions where at least 150 stations are available.

We then examine the uncertainty that arises from the different quality control procedures of the datasets. We compare the results from the three datasets over central North America, Europe, and South Africa, where all the datasets have considerable and comparable spatial coverage (Fig. 12). We investigate the monotonic trends in extreme precipitation and the association with GMST for the three regions. For conciseness, we illustrate the results based on Rx1day, as summarized in Table 5 .

In terms of the long-term trends, the percentages of stations showing significant increasing trends are significantly different from the null hypothesis 


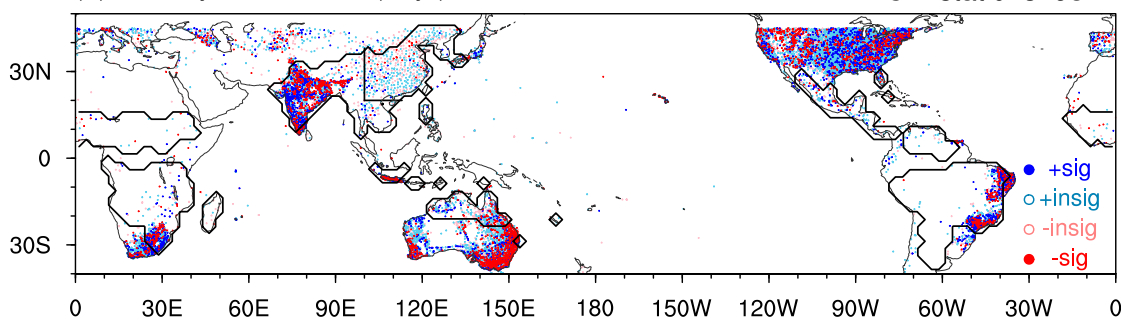

(b) Rx1day: 1951-2010 (30yr)

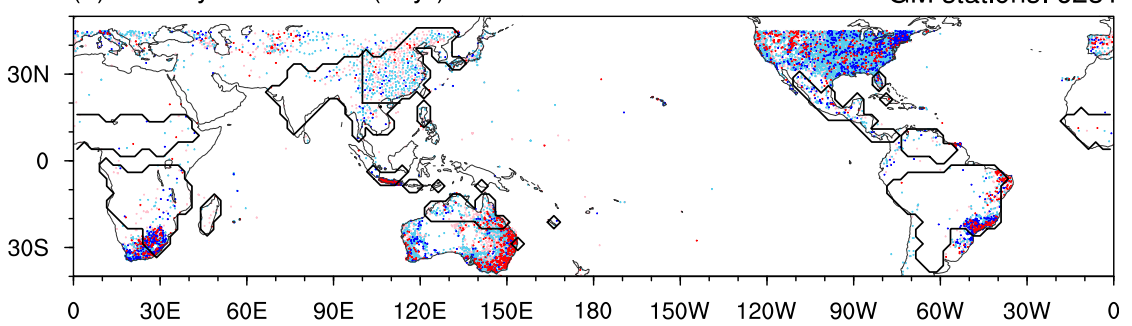

(c) Rx1day: 1951-2010 (40yr)

GM stations: 3355

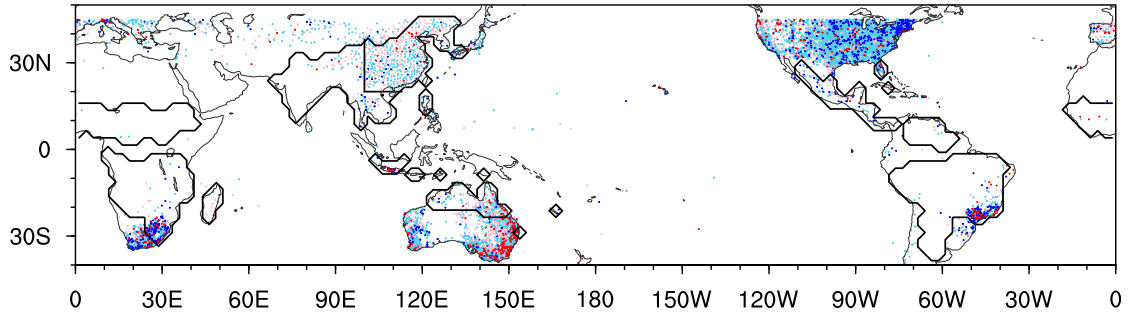

(d) Rx1day: Regional median response rate

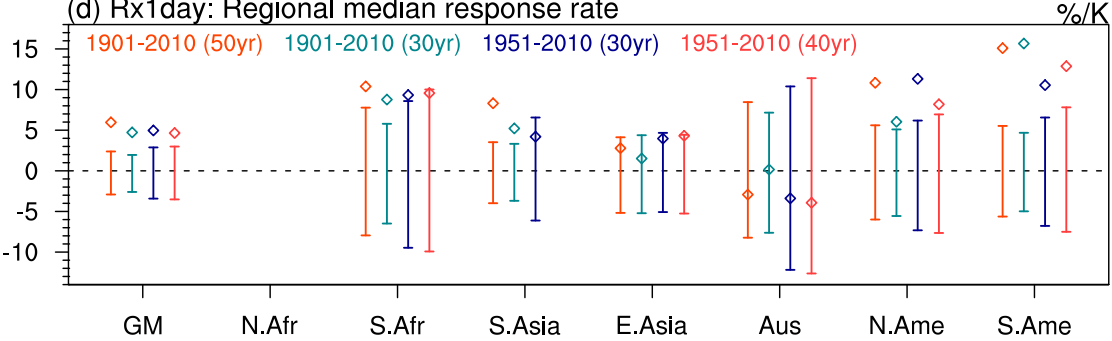

FIG. 11. Association of Rx1day with global mean near-surface air temperature (GMST) changes from the HadEX2-GHCNDEX-CMA merged dataset for different temporal periods. Results are shown for (a) 1901-2010 using stations with at least 30 years of records, (b) 1951-2010 using stations with at least 30 years of records, and (c) 1951-2010 using stations with at least 40 years of records. The blue (red) dots indicate a positive (negative) association with GMST, with filled dark blue (red) dots denoting statistically significant association at the $5 \%$ level indicated by the bootstrap analysis. For visualization purposes, the dark red dots overlay dark blue dots. The numbers of stations available in the global monsoon region are shown in the top right. (d) Regional mean responses of Rx1day to GMST for the global land monsoon regions for different temporal periods $\left(\% \mathrm{~K}^{-1}\right)$. The diamonds and error bars indicate the observations and $95 \%$ ranges from 1000 bootstrap realizations, respectively. Cases where fewer than 150 stations are available are not shown.

distributions for all the three regions, while those showing significant decreasing trends are within the null hypothesis distributions, as revealed consistently by all three datasets (Table 5). In terms of the association with GMST, different datasets reveal similar spatial patterns
(Figs. 12a-c). For the regions as a whole, the percentages of stations showing significant positive and negative associations as well as the regional median response rates are comparable among the datasets, which consistently reveal the significant associations between changes in 
(a) Rx1day: HadEX2-CMA

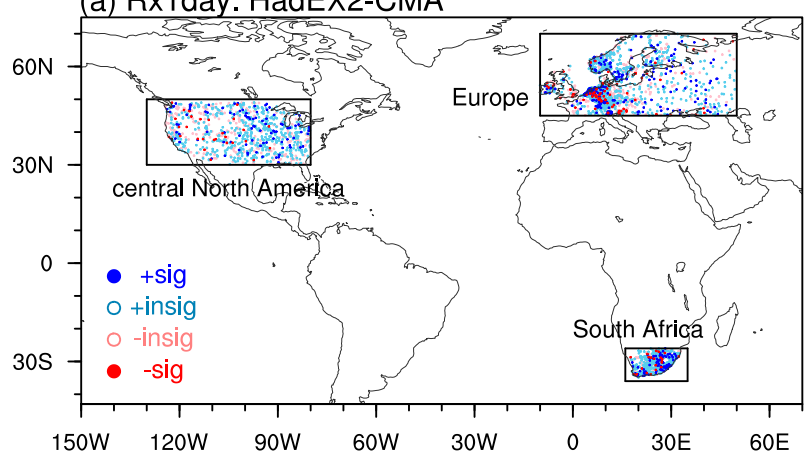

(c) Rx1day: HadEX2-GHCNDEX-CMA merged

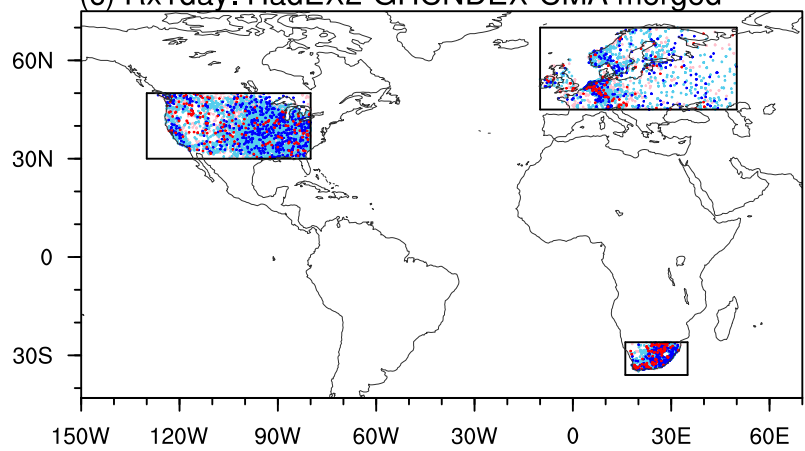

(b) Rx1day: GHCNDEX

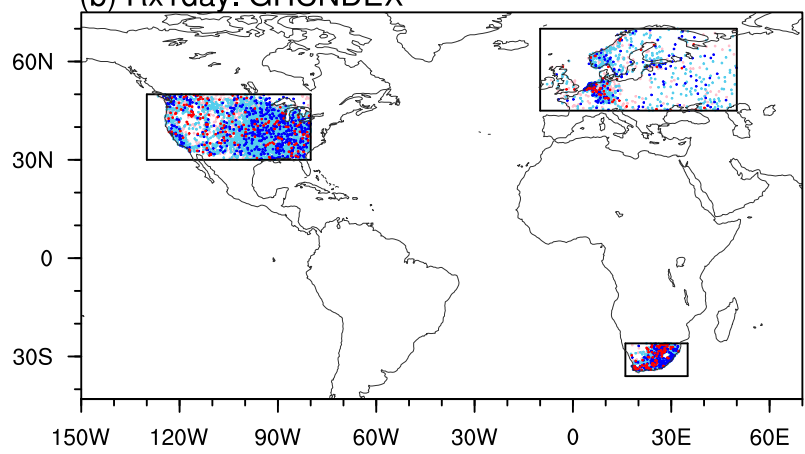

(d) Rx1day: Regional median response rate

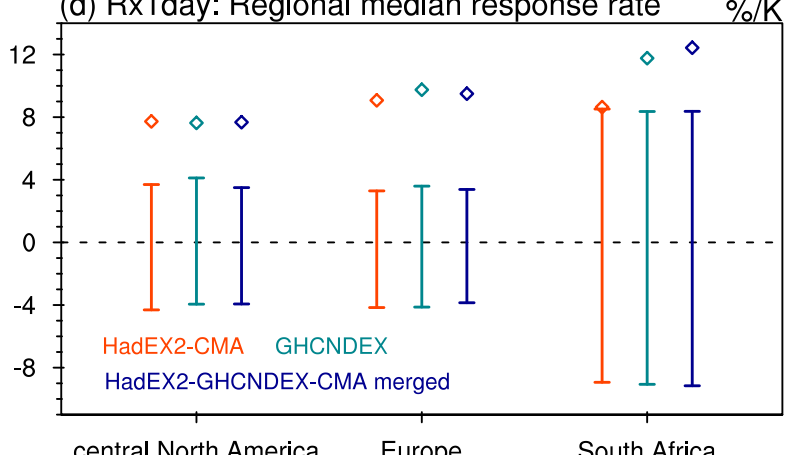

central North America Europe

South Africa

FIG. 12. Association of Rx1day with global mean near-surface air temperature (GMST) changes from (a) HadEX2-CMA, (b) GHCNDEX, and (c) the HadEX2-GHCNDEX-CMA merged dataset for 1901-2010 using stations with at least 50 years of records. The blue (red) dots indicate positive (negative) association with GMST, with filled dark blue (red) dots denoting statistically significant association at the $5 \%$ level indicated by the bootstrap analysis. For visualization purposes, the dark red dots overlay dark blue dots. The black boxes denote the central North America, Europe, and South Africa where all the three datasets have considerable spatial coverage. (d) Regional mean responses of Rx1day to GMST for the central North America, Europe, and South Africa $\left(\% \mathrm{~K}^{-1}\right)$. The diamonds and error bars indicate the observations and $95 \%$ ranges from 1000 bootstrap realizations, respectively.

Rx1day and global warming for the three regions (Fig. 12d and Table 5). Thus, all three datasets consistently reveal significant trends and associations with global warming in extreme precipitation for central North America, Europe, and South Africa over the past century, regardless of the differences in quality control procedures.

To summarize, on the regional scale, the qualitative results on the significance of the trends and associations with global warming of the extreme precipitation are not substantially affected by the use of different datasets, given the considerable and comparable spatial coverages of the datasets. Thus, the results of this study mainly based on the HadEX2-GHCNDEX-CMA merged dataset are qualitatively reliable. Nevertheless, the quantitative differences among the different datasets deserve further attention.

\section{Summary and concluding remarks}

In this study, we examined the long-term changes in extreme precipitation in the global land monsoon regions by employing two global datasets of extremes indices from HadEX2 and GHCNDEX, and daily rain gauge observations over China from the CMA. A merged dataset based on them, HadEX2-GHCNDEXCMA, is also created. These observational datasets represent the most comprehensive, long-running, and high-quality observations available at present. They provide a total of 5066 stations within the global land monsoon region over 1901-2010 with at least 50 years of records, with a median record length of 64 years. In particular, the presence of a significant monotonic trend and association with global mean temperature changes of the extreme precipitation is examined for the monsoon regions. The major conclusions are summarized as follows.

1) For the regional monsoon domains, the southern part of the South African monsoon region, the South Asian monsoon region (dominated by India), the North American monsoon region, and the eastern part of the South American monsoon region have exhibited significant increases in the annual 
TABLE 5. As in Table 1, but for changes in Rx1day over 1901-2010 using stations with at least 50 years of records, using the HadEX2, GHCNDEX, and HadEX2-GHCNDEX-CMA merged datasets, over central North America, Europe, and South Africa, where all the datasets have considerable and comparable spatial coverage. An asterisk (*) indicates the $5 \%$ significance level for percentages of stations with significant increasing or decreasing trends based on the field significance test in column 6 and $5 \%$ significance level for associations with global mean temperature changes based on bootstrap analyses in column 9 .

\begin{tabular}{|c|c|c|c|c|c|c|c|c|}
\hline Region & Dataset & $\begin{array}{c}\text { No. of } \\
\text { stations } \\
\text { included }\end{array}$ & $\begin{array}{c}\text { Median } \\
\text { record } \\
\text { length } \\
(\mathrm{yr})\end{array}$ & $\begin{array}{l}\text { Stations } \\
\text { with } \\
+(-) \\
\text { trends } \\
(\%)\end{array}$ & $\begin{array}{c}\text { Stations } \\
\text { with } \\
\text { significant } \\
+(-) \\
\text { trends } \\
(\% ; 5 \% \\
\text { significance } \\
\text { level } \\
\text { from Mann- } \\
\text { Kendall } \\
\text { test) }\end{array}$ & $\begin{array}{c}\text { Stations } \\
\text { with }+(-) \\
\text { associations } \\
\text { with GMST } \\
(\%)\end{array}$ & $\begin{array}{l}\text { Stations with } \\
\text { significant } \\
+(-) \\
\text { associations } \\
\text { with } \\
\text { GMST }(\% ; 5 \% \\
\text { significance } \\
\text { level from } \\
\text { bootstrap } \\
\text { analysis) }\end{array}$ & $\begin{array}{c}\text { Regional } \\
\text { median } \\
\text { scaling } \\
\text { rate } \\
\left(\% \mathrm{~K}^{-1}\right)\end{array}$ \\
\hline \multirow[t]{3}{*}{$\begin{array}{l}\text { Central } \\
\text { North } \\
\text { America }\end{array}$} & HadEX2 & 833 & 70 & $68.9(31.1)$ & $8.6^{*}(0.4)$ & $66.5(33.5)$ & $11.9(3.4)$ & $7.7 *$ \\
\hline & GHCNDEX & 3995 & 66 & $68.1(31.9)$ & $9.1 *(1.2)$ & $65.3(34.7)$ & $13.6(4.1)$ & $7.6^{*}$ \\
\hline & HadEX2-GHCNDEX-CMA & 4111 & 66 & $68.4(31.6)$ & $9.1 *(1.2)$ & $65.7(34.3)$ & $14.1(4.1)$ & $7.7 *$ \\
\hline \multirow[t]{3}{*}{ Europe } & HadEX2 & 2045 & 60 & $70.1(29.9)$ & $10.9 *(1.0)$ & $64.8(35.2)$ & $14.7(4.2)$ & $9.1 *$ \\
\hline & GHCNDEX & 1177 & 60 & $73.2(26.8)$ & $14.0 *(0.9)$ & $66.9(33.1)$ & $17.7(4.0)$ & $9.7 *$ \\
\hline & HadEX2-GHCNDEX-CMA & 3071 & 60 & $71.0(29.0)$ & $11.9 *(1.0)$ & $65.1(34.9)$ & $15.7(4.2)$ & $9.5^{*}$ \\
\hline \multirow{3}{*}{$\begin{array}{l}\text { South } \\
\text { Africa }\end{array}$} & HadEX2 & 586 & 73 & $69.5(30.5)$ & $10.9 *(1.0)$ & $66.2(33.8)$ & $13.5(3.8)$ & $8.6^{*}$ \\
\hline & GHCNDEX & 950 & 64 & $63.1(36.9)$ & $7.6^{*}(1.7)$ & $63.6(36.4)$ & $20.4(8.2)$ & $11.8^{*}$ \\
\hline & HadEX2-GHCNDEX-CMA & 1413 & 67 & $64.9(35.1)$ & $9.1 *(1.6)$ & $64.5(35.5)$ & $17.3(6.9)$ & $12.4^{*}$ \\
\hline
\end{tabular}

maximum daily precipitation and associations with global warming, with responses to global warming of $\sim 10.4 \%-14.2 \% \mathrm{~K}^{-1}, 7.9 \%-8.3 \% \mathrm{~K}^{-1}, 6.4 \%$ $10.8 \% \mathrm{~K}^{-1}$ and $15.1 \%-24.8 \% \mathrm{~K}^{-1}$ over $1901-2010$, respectively, depending on the methods of estimation, based on 5066 stations with at least 50 years of records. Nevertheless, significant changes in the East Asian and Australian monsoon regions have not emerged yet.

2) For the global monsoon region as a whole, significant increases in extreme precipitation and associations with global warming have also been identified over the past century, but the limited spatial coverage increases the uncertainty of the results.

3) The qualitative results on the significance of the changes on the regional scale are generally robust against the time periods, record lengths of stations, and different datasets used. For different extreme precipitation indices, changes in the moderate extremes show generally weaker associations with temperature compared with the more intense extremes (cf. Rx5day and Rx1day).

There are several sources of uncertainty that should be acknowledged, including those from the spatial and temporal coverages and different datasets: 1) The extreme precipitation observations are limited in the low latitudes, leading to a lack of spatial coverage in the monsoon regions. For the regional monsoon domains, we specify the exact spatial coverages they represent. For the entire global monsoon region, however, the current results should be interpreted with caution due to the lack of observations over the African and American monsoon regions. 2) The results of this study are generally representative of the past century for the entire global monsoon region and most of the subregions. However, the time span for the South Asian (before the 1970s) and East Asian (after the 1950s) monsoon regions is limited. Thus the quantitative responses over these regions should probably not be extended beyond those times. Although the sensitivity analyses in section $3 \mathrm{c}$ using different time periods and record lengths generally agree on the significance of the regional changes in extreme precipitation, the quantitative responses are still partly affected by the multidecadal climate internal variability, as the median record lengths are approximately $40-70$ years for the 1901-2010 period. The influences from the multidecadal climate internal variability are more prominent on the local and regional scales (e.g., the dipolar patterns of change within the East Asian and Australian monsoon regions), with important implications for regional 
adaptation to climate change. 3) The results from the different datasets are qualitatively consistent, but have quantitative differences that arise from the sampling variability and different quality control procedures.

Despite the above uncertainties, the present results have unearthed the significant increases in extreme precipitation over most of the monsoon regions as the climate has warmed, which is also expected to continue under future anthropogenic warming (Kitoh et al. 2013; Freychet et al. 2015; Zhang et al. 2018). Whether and to what extent anthropogenic forcings have influenced the observed changes in extreme precipitation requires a formal attribution analysis, which is still faced with a range of grand challenges (Zwiers et al. 2013). This work serves as a basis for the future detection and attribution of extreme precipitation changes in the monsoon regions.

Apart from the monsoon regions, extreme precipitation changes in the tropics are also important. The limited observations here have shown diverse changes in the different tropical land regions, such as a dominant increase in central North America and South Africa with some scattered decreases, and a dominant decrease in Australia (Figs. 3 and 6). To gain a global perspective of the extreme precipitation changes in the currently poorly sampled tropics, improved monitoring and data sharing within the climate research community are required.

Acknowledgments. This work was jointly supported by the National Key Research and Development Program of China (2018YFC1507701), the National Natural Science Foundation of China (41330423, 41905064), the International Partnership Program of Chinese Academy of Sciences (134111KYSB20160031), and the China Postdoctoral Science Foundation (2018M641450). We thank Dr. Lixia Zhang, Dr. Xiaolong Chen, and Dr. Wei $\mathrm{Li}$ for their comments that helped improve this paper.

\section{REFERENCES}

Adler, R. F., and Coauthors, 2003: The version-2 Global Precipitation Climatology Project (GPCP) monthly precipitation analysis (1979-present). J. Hydrometeor., 4, 1147-1167, https://doi.org/10.1175/1525-7541(2003)004<1147: TVGPCP $>2.0 . \mathrm{CO} ; 2$.

Alexander, L. V., and Coauthors, 2006: Global observed changes in daily climate extremes of temperature and precipitation. J. Geophys. Res., 111, D05109, https://doi.org/10.1029/ 2005JD006290.

Allen, M. R., and W. J. Ingram, 2002: Constraints on future changes in climate and the hydrologic cycle. Nature, 419, 228-232, https://doi.org/10.1038/NATURE01092.

Berg, P., C. Moseley, and J. O. Haerter, 2013: Strong increase in convective precipitation response to higher temperatures. Nat. Geosci., 6, 181-185, https://doi.org/10.1038/ngeo1731.
Bisht, D. S., C. Chatterjee, N. S. Raghuwanshi, and V. Sridhar, 2018: Spatio-temporal trends of rainfall across Indian river basins. Theor. Appl. Climatol., 132, 419-436, https://doi.org/ 10.1007/s00704-017-2095-8.

Bollasina, M. A., Y. Ming, and V. Ramaswamy, 2011: Anthropogenic aerosols and the weakening of the South Asian summer monsoon. Science, 334, 502-505, https://doi.org/10.1126/ science.1204994.

Brown, J. R., A. F. Moise, R. Colman, and H. Zhang, 2016: Will a warmer world mean a wetter or drier Australian monsoon? J. Climate, 29, 4577-4596, https://doi.org/10.1175/JCLI-D-150695.1.

Burke, C., and P. Stott, 2017: Impact of anthropogenic climate change on the East Asian summer monsoon. J. Climate, 30, 5205-5220, https://doi.org/10.1175/JCLI-D-16-0892.1.

Cavazos, T., C. Turrent, and D. P. Lettenmaier, 2008: Extreme precipitation trends associated with tropical cyclones in the core of the North American monsoon. Geophys. Res. Lett., 35, L21703, https://doi.org/10.1029/2008GL035832.

Chang, C. P., Y. Lei, C. H. Sui, X Lin, and F. Ren, 2012: Tropical cyclone and extreme rainfall trends in East Asian summer monsoon since mid-20th century. Geophys. Res. Lett., 39, L18702, https://doi.org/10.1029/2012GL052945.

Collins, M., and Coauthors, 2013: Long-term climate change: Projections, commitments and irreversibility. Climate Change 2013: The Physical Science Basis, T. F. Stocker et al., Eds., Cambridge University Press, 1029-1136.

Donat, M. G., and Coauthors, 2013a: Updated analyses of temperature and precipitation extreme indices since the beginning of the twentieth century: The HadEX2 dataset. $J$. Geophys. Res. Atmos., 118, 2098-2118, https://doi.org/10.1002/ JGRD.50150.

— L. V. Alexander, H. Yang, I. Durre, R. Vose, and J. Caesar, 2013b: Global land-based datasets for monitoring climatic extremes. Bull. Amer. Meteor. Soc., 94, 997-1006, https:// doi.org/10.1175/BAMS-D-12-00109.1.

Durre, I., M. J. Menne, B. E. Gleason, T. G. Houston, and R. S. Vose, 2010: Comprehensive automated quality assurance of daily surface observations. J. Appl. Meteor. Climatol., 49, 1615-1633, https://doi.org/10.1175/2010JAMC2375.1.

Fischer, E. M., and R. Knutti, 2014: Detection of spatially aggregated changes in temperature and precipitation extremes. Geophys. Res. Lett., 41, 547-554, https://doi.org/10.1002/ 2013 GL058499.

_ U. Beyerle, and R. Knutti, 2013: Robust spatially aggregated projections of climate extremes. Nat. Climate Change, 3, 10331038, https://doi.org/10.1038/nclimate2051.

Freychet, N., H. H. Hsu, C. Chou, and C. H. Wu, 2015: Asian summer monsoon in CMIP5 projections: A link between the change in extreme precipitation and monsoon dynamics. J. Climate, 28, 1477-1493, https://doi.org/10.1175/JCLI-D-1400449.1.

Groisman, P. Ya., R. W. Knight, D. R. Easterling, T. R. Karl, G. C. Hegerl, and V. N. Razuvaev, 2005: Trends in intense precipitation in the climate record. J. Climate, 18, 1326-1350, https://doi.org/10.1175/JCLI3339.1.

Hansen, J., R. Ruedy, T. Sato, and K. Lo, 2010: Global surface temperature change. Rev. Geophys., 48, RG4004, https:// doi.org/10.1029/2010RG000345.

Hartmann, D. L., and Coauthors, 2013: Observations: Atmosphere and surface. Climate Change 2013: The Physical Science Basis, T. F. Stocker et al., Eds., Cambridge University Press, 159254. 
Haylock, M. R., and Coauthors, 2006: Trends in total and extreme South American rainfall in 1960-2000 and links with sea surface temperature. J. Climate, 19, 1490-1512, https://doi.org/ 10.1175/JCLI3695.1.

Herold, N., L. V. Alexander, M. G. Donat, S. Contractor, and A. Becker, 2016: How much does it rain over land? Geophys. Res. Lett., 43, 341-348, https://doi.org/10.1002/2015GL066615.

Kendall, M. G., 1955: Rank Correlation Methods. Griffin, 160 pp.

Kennedy, J. J., and Coauthors, 2010: How do we know the world has warmed? [in "State of the Climate in 2009"]. Bull. Amer. Meteor. Soc., 91 (7), S26-S27.

King, A. D., L. V. Alexander, and M. G. Donat, 2013a: The efficacy of using gridded data to examine extreme rainfall characteristics: A case study for Australia. Int. J. Climatol., 33, 23762387, https://doi.org/10.1002/joc.3588.

$\_,-$, and — 2013b: Asymmetry in the response of eastern Australia extreme rainfall to low-frequency Pacific variability. Geophys. Res. Lett., 40, 2271-2277, https://doi.org/10.1002/ grl.50427.

Kitoh, A., H. Endo, K. Krishna Kumar, I. F. A. Cavalcanti, P. Goswami, and T. Zhou, 2013: Monsoons in a changing world: A regional perspective in a global context. J. Geophys. Res., 118, 3053-3065, https://doi.org/10.1002/JGRD.50258.

Lau, K. M., Y. P. Zhou, and H. T. Wu, 2008: Have tropical cyclones been feeding more extreme rainfall? J. Geophys. Res., 113, D23113, https://doi.org/10.1029/2008JD009963.

Lenderink, G., and E. van Meijgaard, 2008: Increase in hourly precipitation extremes beyond expectations from temperature changes. Nat. Geosci., 1, 511-514, https://doi.org/10.1038/ ngeo262.

Li, H., A. Dai, T. Zhou, and J. Lu, 2010: Responses of East Asian summer monsoon to historical SST and atmospheric forcing during 1950-2000. Climate Dyn., 34, 501-514, https://doi.org/ 10.1007/s00382-008-0482-7.

Li, W., Z. Jiang, X. Zhang, and L. Li, 2018: On the emergence of anthropogenic signal in extreme precipitation change over China. Geophys. Res. Lett., 45, 9179-9185, https://doi.org/ 10.1029/2018GL079133.

Lin, L., Z. Wang, Y. Xu, and Q. Fu, 2016: Sensitivity of precipitation extremes to radiative forcing of greenhouse gases and aerosols. Geophys. Res. Lett., 43, 9860-9868, https:// doi.org/10.1002/2016GL070869.

— , Y. Xu, Z. Wang, C. Diao, W. Dong, and S.-P. Xie, 2018: Changes in extreme rainfall over India and China attributed to regional aerosol-cloud interaction during the late 20th century rapid industrialization. Geophys. Res. Lett., 45, 7857-7865, https://doi.org/10.1029/2018GL078308.

Ma, S., and T. Zhou, 2015: Observed trends in the timing of wet and dry season in China and the associated changes in frequency and duration of daily precipitation. Int. J. Climatol., 35, 46314641, https://doi.org/10.1002/joc.4312.

— _ - A. Dai, and Z. Han, 2015: Observed changes in the distributions of daily precipitation frequency and amount over China from 1960 to 2013. J. Climate, 28, 6960-6978, https:// doi.org/10.1175/JCLI-D-15-0011.1.

__ and Coauthors, 2017: Detectable anthropogenic shift toward heavy precipitation over eastern China. J. Climate, 30, 13811396, https://doi.org/10.1175/JCLI-D-16-0311.1.

Min, S., X. Zhang, F. W. Zwiers, and G. C. Hegerl, 2011: Human contribution to more intense precipitation extremes. Nature, 470, 378-381, https://doi.org/10.1038/nature09763.

Mukherjee, S., S. Aadhar, D. Stone, and V. Mishra, 2018: Increase in extreme precipitation events under anthropogenic warming in India. Wea. Climate Extremes, 20, 45-53, https://doi.org/ 10.1016/j.wace.2018.03.001.

New, M., and Coauthors, 2006: Evidence of trends in daily climate extremes over southern and west Africa. J. Geophys. Res., 111, D14102, https://doi.org/10.1029/2005JD006289.

Nigam, S., and Coauthors, 2015: The south-flood north-drought pattern over eastern China and the drying of the Gangetic Plain. Climate Change: Multidecadal and Beyond, C.-P. Chang et al., Eds., World Scientific, 437-359.

O'Gorman, P. A., 2015: Precipitation extremes under climate change. Curr. Climate Change Rep., 1 (2), 49-59, https:// doi.org/10.1007/s40641-015-0009-3.

— , and T. Schneider, 2009: The physical basis for increases in precipitation extremes in simulations of 21st-century climate change. Proc. Natl. Acad. Sci. USA, 106, 14773-14 777, https:// doi.org/10.1073/pnas.0907610106.

Pendergrass, A. G., and D. L. Hartmann, 2014: The atmospheric energy constraint on global-mean precipitation change. J. Climate, 27, 757-768, https://doi.org/10.1175/JCLI-D-1300163.1.

, F. Lehner, B. M. Sanderson, and Y. Xu, 2015: Does extreme precipitation intensity depend on the emissions scenario? Geophys. Res. Lett., 42, 8767-8774, https://doi.org/10.1002/ 2015GL065854.

Risser, M. D., C. J. Paciorek, M. F. Wehner, T. A. O'Brien, and W. D. Collins, 2019: A probabilistic gridded product for daily precipitation extremes over the United States. Climate Dyn., 53, 2517-2538, https://doi.org/10.1007/S00382-01904636-0.

Seneviratne, S. I., and Coauthors, 2012: Changes in climate extremes and their impacts on the natural physical environment. Managing the Risks of Extreme Events and Disasters to Advance Climate Change Adaptation, C. B. Field et al., Eds., Cambridge University Press, 109-230.

Singh, D., M. Tsiang, B. Rajaratnam, and N. S. Diffenbaugh, 2014: Observed changes in extreme wet and dry spells during the South Asian summer monsoon season. Nat. Climate Change, $\mathbf{4}$, 456-461, https://doi.org/10.1038/nclimate2208.

_- M. Bollasina, M. Ting, and N. S. Diffenbaugh, 2018: Disentangling the influence of local and remote anthropogenic aerosols on South Asian monsoon daily rainfall characteristics. Climate Dyn., 52, 6301-6320, https://doi.org/10.1007/ S00382-018-4512-9.

, S. Ghosh, M. K. Roxy, and S. McDermid, 2019: Indian summer monsoon: Extreme events, historical changes, and role of anthropogenic forcings. Wiley Interdiscip. Rev. Climate Change, 10, e571, https://doi.org/10.1002/wcc.571.

Skansi, M., and Coauthors, 2013: Warming and wetting signals emerging from analysis of changes in climate extreme indices over South America. Global Planet. Change, 100, 295-307, https://doi.org/10.1016/j.gloplacha.2012.11.004.

Song, F., and T. Zhou, 2014: The climatology and interannual variability of East Asian summer monsoon in CMIP5 coupled models: Does air-sea coupling improve the simulations? J. Climate, 27, 8761-8777, https://doi.org/10.1175/JCLI-D-1400396.1.

Trenberth, K. E., D. P. Stepaniak, and J. M. Caron, 2000: The global monsoon as seen through the divergent atmospheric circulation. J. Climate, 13, 3969-3993, https://doi.org/10.1175/ 1520-0442(2000)013<3969:TGMAST >2.0.CO;2.

, A. Dai, R. M. Rasmussen, and D. B. Parsons, 2003: The changing character of precipitation. Bull. Amer. Meteor. Soc., 84, 1205-1217, https://doi.org/10.1175/BAMS-84-9-1205. 
, and Coauthors, 2007: Observations: Surface and atmospheric climate change. Climate Change 2007: The Physical Science Basis, S. Solomon et al., Eds., Cambridge University Press, 235-336.

Turner, A. G., and H. Annamalai, 2012: Climate change and the South Asian summer monsoon. Nat. Climate Change, 2, 587595, https://doi.org/10.1038/nclimate1495.

Vecchi, G. A., and B. J. Soden, 2007: Global warming and the weakening of the tropical circulation. J. Climate, 20, 43164340, https://doi.org/10.1175/JCLI4258.1.

Vittal, H., S. Karmakar, and S. Ghosh, 2013: Diametric changes in trends and patterns of extreme rainfall over India from pre1950 to post-1950. Geophys. Res. Lett., 40, 3253-3258, https:// doi.org/10.1002/grl.50631.

von Storch, H., and F. W. Zwiers, 1999: Statistical Analysis in Climate Research. Cambridge University Press, $484 \mathrm{pp}$.

Wang, B., and Q. Ding, 2006: Changes in global monsoon precipitation over the past 56 years. Geophys. Res. Lett., 33, L06711, https://doi.org/10.1029/2005GL025347.

— variation in the tropics. Dyn. Atmos. Oceans, 44, 165-183, https://doi.org/10.1016/j.dynatmoce.2007.05.002.

— J. Liu, H. J. Kim, P. J. Webster, and S. Y. Yim, 2012: Recent change of the global monsoon precipitation (1979-2008). Climate Dyn., 39, 1123-1135, https://doi.org/10.1007/s00382011-1266-z.

,,,,---- S.-Y. Yim, and B. Xiang, 2013: Northern Hemisphere summer monsoon intensified by mega-El Niño/ Southern Oscillation and Atlantic Multidecadal Oscillation. Proc. Natl. Acad. Sci. USA, 110, 5347-5352, https://doi.org/ 10.1073/pnas.1219405110.

Wang, P. X., B. Wang, H. Cheng, J. Fasullo, Z. Guo, T. Kiefer, and Z. Liu, 2017: The global monsoon across time scales: Mechanisms and outstanding issues. Earth-Sci. Rev., 174, 84-121, https://doi.org/10.1016/j.earscirev.2017.07.006.

Westra, S., L. V. Alexander, and F. W. Zwiers, 2013: Global increasing trends in annual maximum daily precipitation. J. Climate, 26, 3904-3918, https://doi.org/10.1175/JCLI-D-12-00502.1.

— , and Coauthors, 2014: Future changes to the intensity and frequency of short-duration extreme rainfall. Rev. Geophys., 52, 522-555, https://doi.org/10.1002/2014RG000464.

Wilks, D. S., 2006: Statistical Methods in the Atmospheric Sciences. Elsevier, 627 pp.
Wu, B., T. Zhou, and T. Li, 2009: Seasonally evolving dominant interannual variability modes of East Asian climate. J. Climate, 22, 2992-3005, https://doi.org/10.1175/2008JCLI2710.1.

Yao, J., T. Zhou, Z. Guo, X. Chen, L. Zou, and Y. Sun, 2017: Improved performance of high-resolution atmospheric models in simulating the East Asian summer monsoon rainbelt. J. Climate, 30, 8825-8840, https://doi.org/10.1175/JCLI-D-16-0372.1.

Yu, R., and T. Zhou, 2007: Seasonality and three-dimensional structure of the interdecadal change in the East Asian monsoon. J. Climate, 20, 5344-5355, https://doi.org/10.1175/ 2007JCLI1559.1.

_ - B. Wang, and T. Zhou, 2004: Tropospheric cooling and summer monsoon weakening trend over East Asia. Geophys. Res. Lett., 31, L22212, https://doi.org/10.1029/2004GL021270.

Zhai, P., X. Zhang, H. Wan, and X. Pan, 2005: Trends in total precipitation and frequency of daily precipitation extremes over China. J. Climate, 18, 1096-1108, https://doi.org/10.1175/ JCLI-3318.1.

Zhang, W., T. Zhou, L. Zou, L. Zhang, and X. Chen, 2018: Reduced exposure to extreme precipitation from $0.5^{\circ} \mathrm{C}$ less warming in global land monsoon regions. Nat. Commun., 9 , 3153, https://doi.org/10.1038/S41467-018-05633-3.

Zhang, X., L. Alexander, G. C. Hegerl, P. Jones, A. Klein Tank, T. C. Peterson, B. Trewin, and F. W. Zwiers, 2011: Indices for monitoring changes in extremes based on daily temperature and precipitation data. Wiley Interdiscip. Rev.: Climate Change, 2, 851-870, https://doi.org/10.1002/wcc.147.

—, H. Wan, F. W. Zwiers, G. C. Hegerl, and S.-K. Min, 2013: Attributing intensification of precipitation extremes to human influence. Geophys. Res. Lett., 40, 5252-5257, https://doi.org/ 10.1002/grl.51010.

Zhou, T., R. Yu, H. Li, and B. Wang, 2008: Ocean forcing to changes in global monsoon precipitation over the recent half-century. $J$. Climate, 21, 3833-3852, https://doi.org/10.1175/2008JCLI2067.1.

_ - D. Gong, J. Li, and B. Li, 2009: Detecting and understanding the multi-decadal variability of the East Asian summer monsoon: Recent progress and state of affairs. Meteor. Z., 18, 455467, https://doi.org/10.1127/0941-2948/2009/0396.

Zwiers, F. W., and Coauthors, 2013: Climate extremes: Challenges in estimating and understanding recent changes in the frequency and intensity of extreme climate and weather events. Climate Science for Serving Society, G. Asrar and J. Hurrell, Eds., Springer, 339-389. 